\title{
A scoping review on the multiplicity of scale in spatial analysis
}

\author{
Taylor M. Oshan, Levi J. Wolf, Mehak Sachdeva, Sarah Bardin, A. Stewart Fotheringham
}

\begin{abstract}
Scale is a central concept in the geographical sciences and is an intrinsic property of many spatial systems. It also serves as an essential thread in the fabric of many other physical and social sciences, which has contributed to the use of different terminology for similar manifestations of what we refer to as 'scale', leading to a surprising amount of diversity around this fundamental concept and its various 'multiscale' extensions. To address this, we review common abstractions about spatial scale and how they are employed in quantitative research. We also explore areas where the conceptualizations of multiple spatial scales can be differentiated. This is achieved by first bridging terminology and concepts, and then conducting a scoping review of the topic. A typology for spatial scale is discussed that can be used to categorize its multifarious meanings and measures. This typology is then used to distinguish what we term 'process scale,' from other types of spatial scale and to highlight current trends in uncovering aspects of process scale. We end with suggestions on how to further build knowledge regarding spatial processes through the lens of spatial scale.
\end{abstract}

Keywords: scale, multiscale, processes, spatial analysis, quantitative geography

JEL codes: C00, C10, C83, Y20, Y50, R12, R23

\section{Introduction}

Scale is a central concept in the geographical sciences and is an intrinsic property of many spatial systems. For decades, the term scale has been used across a diverse set of literature to capture a wide array of phenomena. For instance, scale is used to demarcate or link physical processes that are expressed across landscapes to those that occur at lower levels (e.g., constituent soil patches) or at higher levels (e.g., broader climatic regions). Alternatively, scale is used to refer to the level at which data are collected (e.g. individuals, census tracts, counties) or the range over which spatial processes vary (e.g. local, regional, global). There is also a persistent focus on the identification and quantification of representative scales in an effort to alleviate issues generated by the misspecification of scale (i.e., MAUP, uncertainty). These diverse and often diverging usages of related terminologies have resulted in confusion as to what is meant by scale. Several attempts have been made to bring clarity to the concept of scale, though ambiguity still remains (Quattrochi \& Goodchild, 1997; Sheppard \& McMaster, 2008; Dabiri \& Blaschke, 2019). In particular, the concepts and vocabulary used when simultaneously referring to more than one scale are diverse and inconsistent. Therefore, this 
paper aims to shed light on this important issue by conducting a scoping review and drawing connections between different conceptualizations and deployments of multiple spatial scales.

By exploring the range of scale concepts employed within the geographical sciences, specifically with regard to the terms and methods typically used to operationalize spatial scale, it is possible to uncover novel insights into the nature of scale as used in practice. As a result, rather than adopting any single existing template for organizing knowledge about spatial scale, of which there are many (e.g., Meentemeyer, 1989; Lam \& Quattrochi, 1992; Goodchild \& Proctor, 1997; Marceau, 1999; Gibson et al., 2000; Atkinson \& Tate, 2000; Goodchild, 2001; Dungan et al. 2002; Wu \& Li, 2006; Manson, 2008; Ruddell \& Wentz, 2009; Wu \& Li, 2009; Dabiri \& Blaschke, 2019), we propose using a scoping review of publications from a collection of leading geographical science journals to provide an alternative lens to understand the many concepts of scale employed in quantitative research. The construction of a scoping review has gained popularity, particularly in the medical and health fields, as a formal mechanism for mapping the evolution of knowledge and identifying broad trends in contemporary research (Arksey \& O’Malley, 2005; Khalil et al., 2016; Levac et al., 2010; Munn et al., 2018; Peters et al., 2015; Pham et al., 2014; Tricco et al., 2018). As such, this review attempts to identify what is meant by "multiscale" in scale-centric research by: (1) reviewing key terms and popular expressions of spatial scale; (2) proposing a typology for underscoring the role of scale in various spatial analytical techniques; (3) bringing attention to the lack of consensus surrounding multiscale notions and proposing characteristics to differentiate these notions; and (4) suggesting avenues for future work on measuring process scale and related uncertainties. The review also highlights recent contributions and provides another useful entry point into the vast literature on scale.

In particular, this review focuses on the role of scale multiplicity (i.e., more than one scale) in the pursuit of making inferences about spatial processes. In this context, scale multiplicity has two interpretations. It can refer to what we label type I scale multiplicity or the fact that there are multiple definitions of spatial scale. Alternatively, it can refer to type II scale multiplicity or the idea that the spatial analytical tradition often leverages data at multiple realizations of scales of the same type to learn about spatial processes. Therefore, we explore the proposition that the inferences that can be made about spatial processes depend on the type of scales employed (i.e., type I scale multiplicity), how they are abstracted, and how they are integrated to combine or differentiate information across multiple realizations of scale (type II scale multiplicity). This proposition is similar to that put forward by Dungan et al. (2002) focusing on type I scale multiplicity, though it is extended here to explicitly consider the role of type II scale multiplicity across a variety of contexts. In order to effectively develop this proposition, the first goal of this paper is to distinguish between "data" and "process" notions of spatial scale and discuss how traditionally the spatial scale of data has governed inferences about 
spatial processes. The second goal of this paper is to clarify the various terms for referring to more than one spatial scale (e.g., multiscale versus cross-scale), the types of tasks associated with the manipulation of multiple scales, and how some techniques permit inferences on the scale of spatial processes. A third goal is to bring to the fore the importance of scale in the geographical sciences and motivate the development and use of methods that leverage scale to learn about spatial processes. Achieving these goals will expand our understanding of spatial scale and inform researchers from different traditions of collective opportunities and challenges when conducting spatial analyses and developing new tools.

In pursuit of the above goals, we start with a guided background that provides an overview of previous reviews on spatial scale, examining foundational ideas, and bridging related but sometimes disparate nomenclature. Next, a workflow to gather and analyze an illustrative sample of the literature is outlined. The focus then shifts to typifying facets of scale in empirical research and discussing trends in how scale is both quantified and utilized as a quantitative lens. Finally, some future steps are proposed and some concluding remarks are offered.

\section{A synthesis of terminology and concepts}

Researchers from both the natural and social sciences often analyze phenomena at one or more spatial scales. Indeed, there is by now a large volume of literature describing the concept(s) of spatial scale and detailing developments across various disciplines. On the one hand, domain-specific scale terminologies have arisen in conjunction with substantive research in areas such as landscape ecology (Turner, 1989; Stuber \& Gruber, 2020), remote-sensing (Marceau \& Hay, 1999; Wu \& Li, 2009), and segregation (Fowler, 2016; Johnston et al., 2018). Together, this has perhaps led to the idea that scale is an ambiguous concept and is dependent upon application context (Turner, 1989; Goodchild, 2001; Dabiri \& Blaschke, 2019). On the other hand, there now exist several general treatments of the topic that attempt to bridge subjects and forge a common understanding (e.g., Harvey, 1968; Lam \& Quattrochi, 1992; Marceau, 1999; Atkinson \& Tate, 2000; Dabiri \& Blaschke, 2019). From these efforts, several definitions of spatial scale are frequently encountered across the geographical sciences.

Dabiri and Blaschke (2019) provide a high level synthesis of some previous conceptualizations of spatial scale that yield several common categorizations of the notion of scale: (1) cartographic scale; (2) geographic scale; (3) process (or operational scale); and (4) observation (or measurement) scale ${ }^{1}$. Cartographic scale, which refers to the ratio or proportion of the size

\footnotetext{
${ }^{1}$ They also discuss two additional conceptualizations, modeling scale and policy scale, though there is less consensus around them and they are less frequently encountered. Therefore, they are not pursued here.
} 
of map features to their true size, is perhaps the most traditional and self-consistent ${ }^{2}$ definition. Here "small scale" refers to objects that are rendered on the map with less detail and "large scale" refers to objects that are rendered on the map with more detail. The growth of spatial data and technology in the past few decades has encouraged researchers to seek alternative and sometimes contradictory definitions to accommodate additional aspects of spatial phenomena. For instance, Goodchild (2001) argues a disconnect between the pre-digital era definition of large-scale and adaptations to fit the modern era where large-scale could also refer to the extent of a study area or the physical size of the features involved in a given process. Another example is provided from the field of ecology through a series of short exchanges highlighting the need for both consistency and versatility when referring to scale in ecology (Silbernagel, 1997; Jenerette \& Wu, 2000; Csillag et al., 2000). As a result, Dungan et al. (2002) recommend avoiding the singular term 'scale' and to specifically describe the concepts relevant to a particular analysis. They also suggest differentiating between scale concepts used for collecting data, conducting statistical analysis, and describing phenomena. These calls for more flexible conceptualizations have led to the three contemporary notions of geographic scale, observation scale, and process scale that are often described in the literature, though a large variety of terminologies are used to describe these notions and the nuances amongst them. For example, Table 1 attempts to compare various terms used for similar conceptualizations of scale $^{3}$ and it becomes apparent that with the exception of cartographic scale, there is not a strong consensus within or between notions. Though potentially imperfect, we elect to summarize the many notions identified in the literature under the auspices of geographic scale, observation scale, and process scale (bottom row of table 1) to simplify further discussion. Generally, geographic scale refers to the extent of an area of interest; observation (or measurement) scale refers to the resolution of spatial units across an area of interest; and process scale (or operational scale) is the dimension over which particular processes operate and may refer to their theoretical description or empirical measurement. This latter concept of process scale is of primary interest here and is further differentiated and examined throughout this review.

A more general definition of scale is provided by Marceau (1999) who states that, "scale refers to the spatial dimensions at which entities, patterns, and processes can be observed and characterized". Following this definition, an alternative conceptualization of the latter three definitions of spatial scale mentioned above can be provided in terms of how each modulates

\footnotetext{
${ }^{2}$ An interesting note from (Williams, 1959) clarifies that the representative fraction (i.e., cartographic scale) is only a ratio between the map and the real world at the origin of the map projection and not necessarily across the entire map. Williams also speculates that many researchers and educators fail to highlight this nuance and while it is easy to imagine this speculation is still true, it is unclear what the ramifications are for contemporary pedagogy or research.

${ }^{3}$ We have made our best effort to faithfully categorize previous notions and terminologies and any errors in this pursuit are entirely our own.
} 
spatial entities, patterns, and processes. Often in the geographical sciences, the focus is on collecting and analyzing georeferenced data in order to measure patterns and ultimately inform about spatial processes. In this context, geographic scale and observation scale are the dimensions that modulate spatial patterns. Geographic scale can be thought of as the macro-attribute governing spatial patterns, whereas observation scale can be thought of as the micro-attribute governing such patterns (Goodchild, 2001). The former controls the amount of area over which a pattern can vary, whereas the latter controls the number and nature of the spatial units over which a pattern can be expressed. In contrast, process scale is the dimension that modulates the relationships that generate the data and patterns we ultimately observe. Since we typically cannot directly observe processes, geographic scale or observation scale measurements are often used to characterize the scale that processes occur.

Table 1: Examples of the diverse terminology used in the literature for different notions of scale.

\begin{tabular}{|c|c|c|c|c|}
\hline & \multicolumn{4}{|c|}{ Notions of Scale } \\
\hline Source & $\begin{array}{c}\text { Representative } \\
\text { Fraction / } \\
\text { Detail }\end{array}$ & $\begin{array}{c}\text { Data Extent / } \\
\text { Macro }\end{array}$ & $\begin{array}{l}\text { Data Units / } \\
\text { Micro }\end{array}$ & $\begin{array}{l}\text { Phenomena } \\
\text { / Processes }\end{array}$ \\
\hline Lam \& Quattrochi, 1992 & Cartographic & $\begin{array}{l}\text { Geographic or } \\
\text { Observation }\end{array}$ & Resolution & Operational \\
\hline Marceau, 1999 & Cartographic & Absolute / Extent & $\begin{array}{c}\text { Absolute / Operational } \\
\text { / Grain }\end{array}$ & Relational \\
\hline Atkinson \& Tate, 2000 & Cartographic & $\begin{array}{l}\text { Measurement / } \\
\text { Coverage }\end{array}$ & $\begin{array}{c}\text { Measurement / } \\
\text { Observation / Support }\end{array}$ & Variation \\
\hline Dungan et al. 2002 & Cartographic & $\begin{array}{l}\text { Sampling / } \\
\text { Analysis }\end{array}$ & $\begin{array}{l}\text { Sampling / } \\
\text { Analysis }\end{array}$ & Phenomena \\
\hline Ruddell \& Wentz, 2009 & Cartographic & Geographic & Resolution / Support & Operational \\
\hline Dabiri \& Blaschke, 2019 & Cartographic & Geographic & $\begin{array}{l}\text { Observation / } \\
\text { Measurement / } \\
\text { Resolution }\end{array}$ & Operational \\
\hline This Manuscript & Cartographic & Geographic & Observation & Process \\
\hline
\end{tabular}




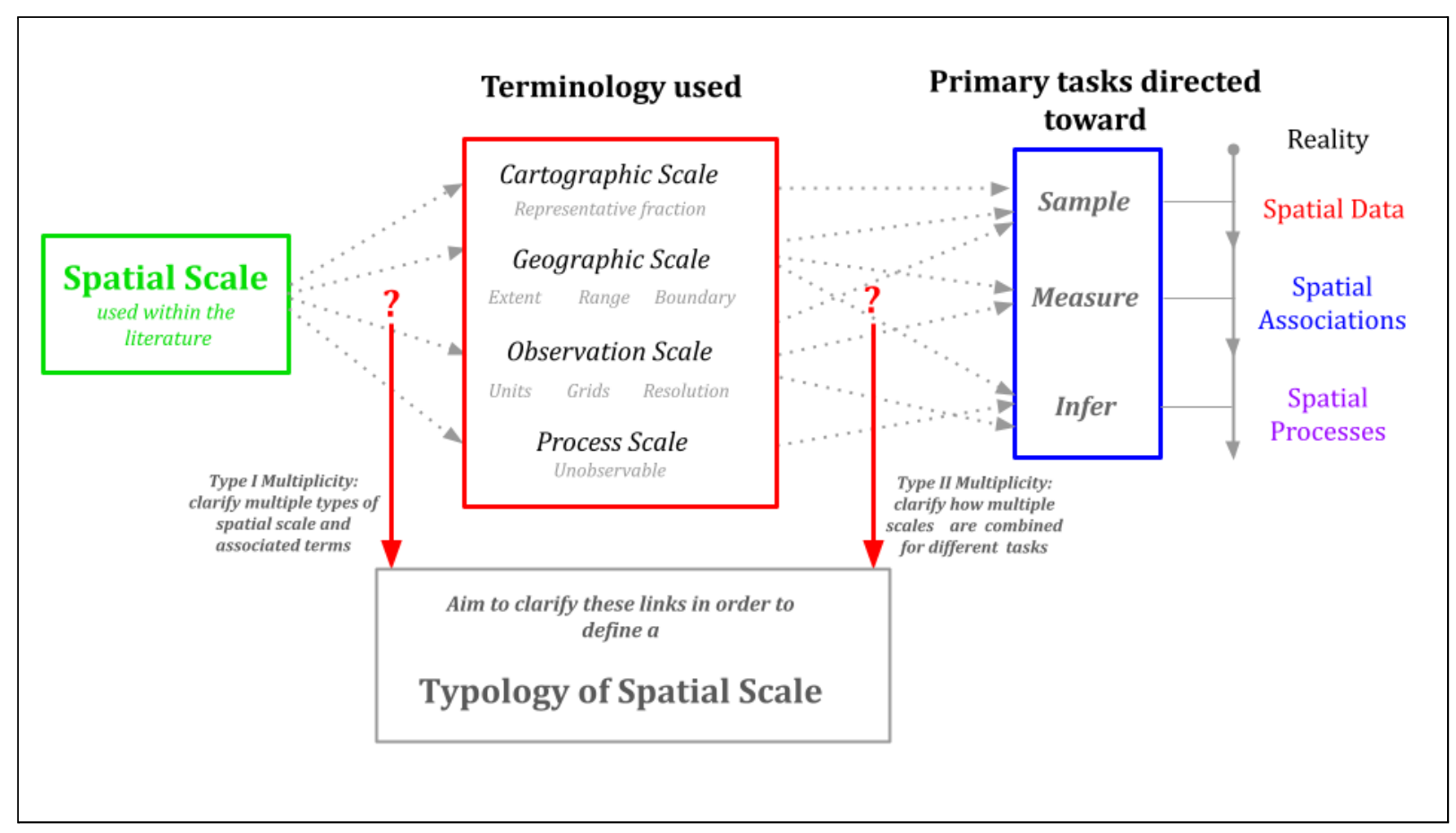

Figure 1: Flowchart outlining goals of the study.

Atkinson and Tate (2000) provide another framework based on a geostatistical perspective to conceptualize spatial scale. In their view, the dominant scale of spatial variation (i.e. inferred process scale) measured across spatial data is at least partially determined by the scales of measurement (i.e., observation scale) used to obtain the data. Atkinson and Tate also define "multiscale" as the multiple scales of measurement at which data may be observed. This raises an important issue because multiscale could equally refer to multiple geographic scales, multiple observation scales, or multiple process scales, with an emphasis on empirical data or theoretical processes, each of which may refer to different types of connections between and within spatial systems. For example, Gibson et al., (2000) describe the scale-related term of hierarchy and how multiple levels are connected across constitutive hierarchies, such as individuals to families or cities to regions, since phenomena at any one level are affected by levels above and below. In contrast, in contemporary geographically-weighted models, multiscale does not refer to multiple levels of measurement. Instead, relationships between variables and an outcome can change quickly or slowly with distance while the level of measurement remains constant (Fotheringham et al. 2017). This means that some relationships in a multivariate model may be 'local' relationships that change within a single city or neighborhood with many inflection points across the study area, whereas others may be 'regional' relationships that vary slowly with only one or two inflection points. Others still may be 'global' relationships which hold for all locations. Thus, "multiscale" in the former sense refers to the scale of a set of separate connected entities whereas the latter sense refers to the 
scale of process variation. These examples are further distinguishable from multiscale technologies that allow data to be efficiently stored, accessed, and visualized. Further confusion may also arise from related expressions for more than one scale, such as multiscale, cross-scale, multiple scales, multiscalar, and scale-invariant.

Given the diversity that exists in the literature regarding the conceptualization and operationalization of scale, in what follows we attempt a comprehensive yet bounded review of the use of scale by focusing on a selection of core geographic journals. The overall goals and organizational logic of this review are summarized in Figure 1, which illustrates the use of the literature to extract examples on the many uses of scale and distill them into a typology. From left to right, we focus on identifying how the different types of scale are employed (type I scale multiplicity), how multiple realizations of scale are integrated or differentiated (type II scale multiplicity), and the core tasks informed by these aspects of scale.

\section{Selecting a 'scale' corpus from the geographic literature}

To examine the use of 'scale' in the geographic literature, five journals were selected as a representative sample of the much larger corpus of geographic knowledge: (1) The Professional Geographer (TPG); (2) The Annals of the American Association of Geographers (AAAG); (3) Applied Geography (APGEO); (4) Geographical Analysis (GEAN); and (5) The International Journal of Geographic Information Science (IJGIS). Collectively, these journals represent a wide breadth of contributions from across the discipline and a diversity of application areas. Although literature from other disciplines contains important developments on the conceptualization and quantification of spatial scale, such outlets tend to be more narrow compared to the geographical journals selected here, and placing meaningful bounds across an array of discipline-specific outlets would likely prove to be a very difficult task that is outside the scope of this work.

The inclusion of each selected journal toward the goal of this review is now briefly justified. As the premier journal of the American Association of Geographers and with over 100 years of contributions, the AAAG is a core outlet for essential geography research in four categories: Geographic Methods; Human Geography; Nature and Society; and Physical Geography, Earth and Environmental Sciences. Hence, it features leading research that privileges traditional and contemporary geographic thinking across the entire spectrum of sub-disciplines and specializations. A similar breadth is covered by TPG; however, it favors shorter submissions that prioritize fresh approaches and therefore it serves as a platform for making poignant statements and presenting straightforward applications and issues. With a slogan of "Putting 
the World's Human and Physical Resource Problems in a Geographical Perspective", and an eponymous title, the central aim of APGEO is to contribute towards solving practical problems through the application of geographic theories and methods. As such, it is particularly suited to offer a glimpse at how geographic methodologies are deployed in the wild and to observe connections between geography and other fields. Meanwhile, GEAN provides another point of view as the first journal (since 1969) in its specialty area of the analytical traditions, such as spatial data analysis and spatial statistics, in a world now awash in forums focused on data science and applied computing. It is an excellent resource for tracing the lineage of quantitative thought and techniques exported from within the discipline. Finally, the IJGIS serves as an encompassing exchange for all facets of the rapidly growing and maturing field of Geographic Information Science (GIScience). Given its emphasis on all aspects of geographic tools and techniques for handling spatial data and quantifying spatial patterns and processes it is ideal for capturing the pulse of GIScience as it develops and diffuses across domains. The scope of each journal is further described in Table A.1 of the Appendix based on excerpts obtained directly from their official web pages. Though there is some overlap, these five journals represent sufficiently different perspectives to justify their separate inclusion and, collectively, they provide a strong base upon which to build an initial understanding of the quantitative use and development of spatial scale that can be subsequently expanded to become more holistic and comprehensive.

Manuscripts published through 2021 were obtained from each of the five selected journals by querying each for the keywords "scale" or "multiscale" using the search utility on their respective web pages. Though this returned hundreds of results, the 100 most relevant ${ }^{4}$ hits returned by each journal (500 total) were initially selected for further screening - beyond this threshold, there were no papers that explicitly or implicitly made any reference to scale in their title or abstract. Next, 194 manuscripts were selected from the initial 500 by excluding those that: (i) only described the size of the study area (i.e., large-scale or small-scale, continental-scale, street-scale); (ii) were primarily about qualitative scale (i.e., scales of power); or (iii) focused exclusively on non-spatial scales (i.e., economies of scale or temporal scales) $)^{5}$.

\section{A typology of how 'scale' is used in practice}

The selected corpus was reviewed and categorized based on the types of spatial scale (cartographic, geographic, observation or process) considered as the primary focus (red box in

\footnotetext{
${ }^{4}$ Each of the journal databases allowed the results to be sorted by relevance, though they do not provide an explanation on how they quantify relevance.

${ }^{5}$ Book reviews were also excluded as the focus here was on original research contributions. All 161 selected manuscripts are included in the references, including those few that were not directly cited in the text.
} 
Figure 1). Almost half of the manuscripts (42\%) focused on observation scale and measuring the effects of varying resolutions of spatial units on the results of spatial analyses. The next largest focus (32\%) was on geographic scale, followed by process scale (18\%) and finally by cartographic scale (8\%). Given the minimal use of cartographic scale, which was sometimes used in conjunction with or as a synonym for other types of scale (e.g., Rendenieks et al., 2017), it is not a central focus moving forward. Furthermore, an in-depth exploration of process scale is reserved for the following section. The rest of this section is therefore centered on highlighting popular themes detected in the corpus and the role of observation and geographic scales.

Manuscripts in the corpus were reviewed by the research team and categorized based upon the team's expertise and experience into a set of primary themes and topics. Specifically, each manuscript was assigned at least one topic label, though up to three topic labels were permitted to accommodate interdisciplinary research and to accommodate the relatively subjective nature of the labeling process. Labels were identified by the team on a rolling basis as the literature was reviewed, with topics occasionally being merged or split to maintain a minimally sufficient subset able to represent the themes within each manuscript and across the entire corpus. This ultimately resulted in 18 topics, which are presented in Appendix Table A.2, along with the tally of the number of times each topic was observed in each journal and across all five journals, though the topic of primary interest moving forward is Data Structures \& Analytics.

A similar deductive approach was used to disaggregate the Data Structures \& Analytics topic into sub-topics, which are tallied in Appendix Table A.3. Contributions were categorized based on different types of methods and actions that depend on similar scale concepts, again allowing manuscripts to belong to more than one category. Additionally, a distinction was made between "cross-scale" methods, where multiple spatial scales are manipulated independently or compared, and "multiscale" methods, where different spatial scales (of any kind) were measured or captured simultaneously. The focus was to group contributions to identify general patterns rather than sort them into mutually exclusive and exhaustive categories. In the remainder of this section, all in-text citations come only from the assembled corpus, though some related references from outside the corpus are provided in footnotes for those interested in further details.

As one of the most frequent sub-topics within the theme of Data Structures and Analytics, Cartography \& GIS encapsulates methods for computer cartography and geographic information systems. It has two prevailing themes. First, these contributions were almost exclusively about integrating information obtained at different scales (e.g., Li \& Zhou, 2012; Yue et al., 2015; Zhang et al., 2015; Zhang et al., 2021). Second, the most frequent task associated with these efforts was to generalize geographic features (e.g., topography or road 
network) or maintain consistent relationships between them for efficient and consistent viewing, storage, and access across scales (e.g., van Oosterom, 1995; Jones, 1996; Du et al., 2010; Jiang et al., 2013; van Oosterom \& Meijers, 2014; Jiang, 2015; Clarke, 2016; Liu et al., 2020). Other tasks included capturing space-time change (Plumejeaud et al., 2011) and feature identification (Deng \& Wilson, 2008). Though cartography and cartographic systems were at the center of this category, it is interesting that the cartographic definition of scale (i.e., representative fraction) was not. Rather, there were examples where geographic scale (e.g., Deng \& Wilson, 2008; Hoover et al., 2019) and observation scale (e.g., Du et al., 2010; van Oosterom \& Meijers, 2014) were used, as well as examples where the cartographic definition was employed (e.g., Stoter et al., 2011; Chen \& Zhou, 2013; Peng et al., 2021). In one case, the scale definition was not explicit despite the research focusing on multiscale data (Sinha \& Silavisesrith, 2012). Surprisingly, there was only one instance of a data model for working across both spatial and temporal scales (Van de Weghe et al., 2014).

Two tasks differentiate the Remote Sensing \& Image Processing sub-topic from the Cartography \& GIS sub-topic. The first task focuses on the classification of image pixels or point clouds (e.g., Dekavalla \& Argialas, 2017; Zhao et al., 2018; Guo \& Feng, 2018). For example, different geographic scales (i.e., distance-based neighborhoods) can be used to create 2D images from 3D point clouds that are each fed into a convolutional neural network to extract a set of features that are assembled into a multiscale feature set for subsequent classification (Zhao et al., 2018). Alternatively, a 3D point cloud can be resampled at different observation scales (i.e., number of cubes) that nest into a hierarchy of geographic scales (i.e., cube size) to form a multiscale point cloud pyramid that is able to reduce the effects of noise and varying point densities when classifying points (Guo \& Feng, 2018). Meanwhile, Dekavalla \& Argialas (2017) enhance the automatic classification of land surface features by using an adaptive geographic scale (i.e., pixel-specific radius) that is efficient across input observation scales (i.e., resolution). In contrast, the second task focuses on the identification of objects from imagery and does not appear to explicitly define scale, instead using the notions of scale to refer to the size of objects (number of pixels) and multiscale to refer either the comparison of analyses for different size objects (i.e., cross-scale) or to the bottom-up formation of larger objects from smaller ones (Stefanidis et al., 2002, Drăguţ et al., 2010; Chen et al., 2011; Argyridis \& Argialas, 2019). Overall, these tasks described under the banner of Cartography \& GIS and Remote Sensing \& Image Processing typically focus on multiscale data fusion and integration.

Profiling is an umbrella term used here to refer to any method that computes a statistic or measure as a function of geographic scale or observation scale. Perhaps the most well known example is the variogram or semivariogram, which measures the spatial variation as a function of different geographic scales (i.e., ranges) (e.g., Phillips, 1988; De Cola, 1994; Liu \& Jezek, 
1999; Goovaerts et al., 2005; Zhang \& Zhang, 2011; Lloyd, 2012, Lloyd, 2016). Other profiles may alternatively be based on spatial autocorrelation statistics (Zhang \& Zhang, 2011), entropy (Appleby, 1996), diversity indices (Zhang et al., 2013), isolation statistics (Östh et al., 2015), fractal dimension (Lam \& Quattrochi, 1992; De Cola, 1994), percentages (Petrović et al., 2018), or cumulative probability distributions (Wong, 2001). These values are often computed as a function of geographic scale metrics, most commonly 'global' distance lags between all observations (Phillips, 1988; Lam \& Quattrochi, 1992; Liu \& Jezek, 1999; Goovaerts et al., 2005; Zhang \& Zhang, 2011) or 'local' aggregates for each observation across distance bands, within a moving window, or based on a population-based number of nearest neighbors for an individual-contextual approach (Wong, 2001; Lloyd, 2012; Östh et al., 2015; Petrović et al., 2018). However, values are also sometimes computed as a function of observation scale (i.e., resolution or spatial unit size) (De Cola, 1994; Appleby, 1996; Zhang \& Zhang, 2011; Zhang et al., 2013). All of these profiling variants involve cross-scale analysis, though Petrović et al. (2018) carry out an explicitly multiscale analysis by measuring the location-specific entropy across profiles for 101 geographic scales (i.e., extents). Furthermore, while most of the profiling examples here focused on comparing values across scales, a few contributions focused more explicitly on selecting an 'optimal' scale (e.g., Zhang \& Zhang, 2011; Zhang et al., 2013). ${ }^{6}$

The Clustering sub-topic pertains to a variety of analytical tasks that includes: (i) detecting whether spatial units are clustered; (ii) determining which spatial units are clustered; and (iii) deciding how spatial units should be clustered into larger aggregate spatial units or groups. Task (i) is most frequently achieved using traditional 'global' point pattern analysis techniques where clustering tests are typically based solely on location information (e.g., Smith, 2004) and spatial autocorrelation statistics when clustering is based on location information and an observed attribute information (e.g., Chou, 1991). Task (ii) usually employs focused or 'local' versions of point pattern analysis or spatial autocorrelation statistics ${ }^{7}$, as well as scan statistics, that evaluate each spatial unit at a fixed observation scale while conditioning on or exploring a series of geographic scales (i.e., extents) to identify clusters from randomness (e.g., Wong, 2001; Shiode \& Shiode, 2009; Rogerson \& Kedron, 2012; Rogerson, 2015; Westerholt et al., 2015; Carr et al., 2019; Li et al., 2019; Liu et al., 2019). In this case, cross-scale analyses are typically used for comparing results across observation scales or for selecting an 'optimal' geographic scale. However, more explicitly multiscale techniques in this context are those that incorporate information found at several geographic scales into a metric (e.g., Shiode \& Shiode, 2009; Westerholt et al., 2015; Liu et al., 2019; Griffith, 2021; Yu \& Fotheringham, 2021). Finally, task (iii) is often referred to as regionalization and entails creating larger (i.e.,

\footnotetext{
${ }^{6}$ This is an exceptionally long-lived strategy for geographers (see Fotheringham \& Wong (1991), p. 1042) for addressing the 'empirical effects' of theoretical ambiguity about scale (Wolf et al. 2021, p. 3).

${ }^{7}$ For more on these techniques, see (Getis \& Ord, 1992; Anselin, 1995; Boots \& Okabe, 2007)
} 
coarser) observation scales by combining or grouping units from smaller (i.e., finer) observation scales (e.g., Mu \& Wang, 2008; Meng et al., 2021). At the root of regionalization methods is a tradeoff between the level of detail (i.e., fewer regions means less detail) and noise (i.e., fewer regions averages out extreme values) in spatial patterns and processes that is often driven by minimizing variation within regions and maximizing variation between them ${ }^{8}$. In this context, one example used multiscale to refer to an algorithm for searching across geographic scales (i.e., cross-scale) rather than the explicit integration of entities or relationships at different scales (Meng et al., 2021).

Decomposition Models include an array of techniques that incorporate univariate statistics, multiple regression, multilevel models, and geographically weighted models. Since many of these techniques overlap, they are therefore discussed collectively in terms of their shared qualities and defining characteristics. By Decomposition, we refer to how a process is partitioned into contributions from different but interrelated components, either at different scales and/or between different variates in a multivariable process. Multilevel models are one type of Decomposition method that extracts the contribution of information from individual 'levels' towards a statistical pattern or measure, where levels are different observation scales (i.e., resolution or grain). Since the levels are typically hierarchically nested and linearly additive, multilevel models are intrinsically multiscale as they always incorporate more than one spatial scale into a single analysis of a variable of interest ${ }^{9}$. Furthermore, the main goal of these methods is the expression and comparison of contributions at a handful of prespecified scales rather than the selection of a single optimal scale across a large range. It is often implied though that the level with the largest variation is the observation scale at which further study is required. Multilevel models are further differentiated by their focus on either a univariate statistic or a multiple regression context. The former focuses on decomposing a single variable or measure as a function of itself, such as spatial variability (Oliver \& Webster, 1986; Collins \& Woodcock, 2000), moving window averages (Pigozzi, 2004), the statistical likelihood (Kolaczyk \& Huang, 2001), diversity and dissimilarity indices (Wong, 2003; Manley et al., 2019), or entropy (Phillips, 2005; Batty, 2010; Leibovici \& Birkin, 2015). In contrast, the latter focuses on decomposing a variable as a function of other variables (e.g., Duncan \& Jones, 2000). More recent work found in this review corpus extended these types of multilevel multiple regression models to examine contributions from different groups (i.e., categories) across scales (Manley et al., 2015), modeling spatially clustered survey data based on attributes of individuals, neighborhoods, wider regions, and heterogeneities across them (Ma et al., 2018), the development of hierarchical spatial autoregressive models to capture dependencies at each level (Dong \& Harris, 2015), and a locally adaptive extension (Dong et al., 2020).

\footnotetext{
${ }^{8}$ For more on regionalization, the reader is referred to (Duque et al., 2007).

${ }^{9}$ The theory on variance partitioning in multilevel models is set out by Goldstein et al. (2002).
} 
It is also possible for Decomposition Models to focus on the contribution of information from different geographic scales (i.e., extents) rather than different observation scales (i.e., resolution or grain). For example, Goovaerts et al. (2005) use decomposed semivariograms (i.e., variation across distance lags) to identify and model local and regional components of cancer risk and find that risks have qualitatively different associations at different scales that could otherwise go undetected. Another example by Johnston et al. (2004) conducts factor analysis and partial regression coefficient reconstitution to compare potential neighborhood effects among individual voting patterns measured at several k-nearest neighbors aggregates (i.e., population-based extents). These cross-scale analyses both depend upon the analyst to select the 'interesting' scales for further investigation. In contrast, geographically weighted regression (GWR) models are able to computationally search a continuous range of distances or an exhaustive set of k-nearest neighbors to select or seek for an optimal geographical scale at which to find local associations based on a model fit criterion such as cross validation or the Akaike Information Criterion (AIC) ${ }^{10}$. This optimal geographical scale is then often interpreted as an indicator of process scale. A recent multiscale extension to GWR allows the identification of a unique indicator of scale for each response-covariate relationship in the model (Fotheringham et al., 2017). This means that within a single model some associations may be indicated as 'global' and having no smaller (geographic) scale effect, while others might be treated as regional or local. The importance of accounting for these type of multiscale effects for accurately capturing spatial process has been highlighted and also shown to be similar to multilevel models with a global level (i.e., no spatial variation) and a local level with an observation scale equivalent to the coordinates of sample locations or centroids (Murakami et al., 2018; Wolf et al., 2018).

The Scaling \& Fractals sub-topic focuses on linking the distribution of an attribute or the calculation of a metric across levels of detail based on the assumption that there is some pattern or process that remains consistent across them, with levels implicitly or explicitly corresponding to different spatial scales. As such, there is some overlap between this sub-topic and that of Profiling. Scaling inquiries also often entail comparing observed distributions to theoretical distributions to investigate the degree of scaling in an attribute (i.e., size, length, connectivity, number of events, configuration). In particular, fractals have influenced the concept of scaling and Goodchild and Mark (1987) discuss three notions that incorporate fractals into spatial analysis ${ }^{11}$. The first notion concerns the response of a measure to explicitly defined spatial scales. Since fractal dimension is used to characterize the complexity, irregularity, or roughness of a geographic feature, this intuition can be extended to examine

\footnotetext{
${ }^{10}$ For an introduction to GWR, see (Brunsdon et al., 1996; Fotheringham et al., 1998; Fotheringham et al., 2002; Oshan et al., 2019).

${ }^{11}$ For more on scaling, fractals, and their interaction, readers are referred to (Batty et al., 1989; Lam \& Quattrochi, 1992; Sun et al., 2006; Batty, 2010; Jiang \& Brandt, 2016)
} 
how different values of fractal dimension or domains of consistent fractal dimension across spatial scales may be associated with different spatial processes (i.e., Profiling). An example of fractal dimension as a function of geographic scale is provided by Lam \& Quattrochi (1992) while an example of fractal dimension as a function of observation scale is provided by Appleby (1996). The second notion is that of self-similarity or the repetition of statistical patterns at different scales (e.g., Ovando-Montejo et al., 2021), which has been used to simulate terrain and geomorphological processes, as well as develop alternative null models to compare against them. The third notion pertains to the recursive subdivision of space that leverages self-similarity to produce space-filling patterns, inspiring the development of efficient spatial data structures.

More recently, Jiang and colleagues (Jiang et al., 2013; Jiang, 2013; 2015) demonstrate that the Pareto-like distribution of many geospatial phenomena provides the basis for cognitive mapping and cartographic generalization across intrinsic hierarchical observation scales based on recursive 80-20 splits of an attribute and Jiang \& Ren (2019) suggest a multiscale topological representation of space that captures the relationships within and between intrinsic hierarchical geographic scales. Underlying this later technique is the Ht-index, which expresses hierarchical levels of scales, in comparison to the fractal dimension, which expresses the degree of heterogeneity for a level (Jiang \& Yin, 2014). Another recent direction develops the concept of multifractals, which acknowledges that fractal properties of an attribute may vary across space, generating multiscale patterns (Tan et al., 2021).

Changing the support size (i.e., observation scale) of data or models is referred to as Rescaling, or more specifically, upscaling (i.e., aggregating) \& downscaling (i.e., disaggregating) depending on whether the units are becoming coarser or finer, respectively ${ }^{12}$. The focus is often on rescaling data that are then analyzed or modeled at different observation scales where observations are translated into a new scale through averaging, smoothing, extrapolating, or interpolating (e.g., Bednarz \& Ralston, 1982; De Cola, 1994; Atkinson \& Tate, 2000; Yoo \& Trgovac, 2011; Buck, 2017; Zhang et al., 2019). An alternative approach proposes to calibrate a geostatistical model (i.e., variogram) for one observation scale and then directly upscale or downscale the modeled variation across geographic scales (i.e., distance lags) using regularization rather than rescaling the data and modeling it at the new scale (Atkinson \& Tate, 2000). Rescaling may be seen as a contrast to multilevel models that incorporate data across multiple scales rather than harmonizing data to a single scale (e.g., Wilson et al., 2011). In addition, the smoothing that results from some upscaling methods typically results in information loss and evidence suggests that analytical results may be more sensitive to

\footnotetext{
${ }^{12}$ Adding to the confusion of terminology, in image processing (e.g. Kopf et al. 2013), 'downscaling' refers to reducing the resolution of the image. For example, when referring to reducing the resolution of an image, the image is 'downscaled', but this reduces detail, which corresponds to 'upsampling' in the literature we review here.
} 
rescaling than using data directly measured at a coarser observation scale (Atkinson \& Tate, 2000; Zhang et al., 2019).

The modifiable area unit problem (MAUP) refers to the sensitivity of data and analytics to the spatial units or support upon which they are measured ${ }^{13}$. These effects are traditionally grouped into two categories with one focusing on the sensitivity to changes in zonal boundaries (e.g., Burden \& Steel, 2016) and another focusing on the sensitivity to changes in scale, which could include either varying observation scales within a single geographic scale (e.g., Chou, 1991; Mu \& Wang, 2008; Burden \& Steel, 2016) or varying geographic scales for a fixed observation scale (e.g., Wong, 2001). However, in practice it appears that the scale aspect of the MAUP is more often investigated by the former task of varying observation scales within a single geographic scale (e.g., Kwan \& Weber, 2008; Houston, 2014). The latter task of varying geographic scales for a fixed observation scale may perhaps be less frequently investigated under the guise of the MAUP because qualitative shifts in patterns and processes at different geographic scales starts to become more related to hierarchy theory ${ }^{14}$, which is less apparent in this corpus. Only a few manuscripts sought to specifically examine the MAUP effects of a particular method ${ }^{15}$, which is closely related to the tasks highlighted in the Profiling and Clustering sub-topics, with many more contributions indirectly incorporating an analysis of the MAUP by making cross-scale comparisons. Fowler et al. (2020) demonstrate the potential uncertainty and contextual fallacy of using relatively aggregregate geographies (e.g., census delineations) rather than individual or ego-centric ${ }^{16}$ neighborhood definitions. While there are no general solutions to mitigate the $M A U P$, strategies to account for the related sensitivities typically suggest more explicitly multiscale approaches that integrate a distribution of results across scales (e.g., Wong, 2001; Burden \& Steel, 2016).

There were two flavors of contributions centered on simulation models using agents or cellular automata. The first focused explicitly on the sensitivity of results to spatial scales. These examples present cross-scale comparisons, focusing on sensitivities associated with different observation scales (Jantz \& Goetz, 2005; Bonnell et al., 2016) and on sensitivities associated with different geographic scales (Kang \& Aldstadt, 2019), or both (Wu et al., 2019a). The second approach focused on incorporating different types of agents for entities that exist at different scales and interact across scales, providing a multiscale analysis of complex systems (An et al., 2005; Tang \& Bennett, 2010; Xu et al., 2020).

\footnotetext{
${ }^{13}$ A few central references describing the MAUP are (Openshaw \& Taylor, 1979; Arbia, 1989; Fotheringham \& Wong, 1991; Jelinski \& Wu, 1996; Dark \& Bram, 2007).

${ }^{14}$ For more on hierarchy theory, readers are referred to (O'Neill \& Smith, 2002; Jenerette \& Wu, 2010; Wu, 2013; Allen \& Starr, 2017)

${ }^{15}$ This statement does not include manuscripts examining the MAUP effects of a particular relationship (i.e., applied focus over methodological focus).

${ }^{16}$ See Hipp \& Boessen (2013) in addition to papers from the corpus.
} 
Rather than developing or applying methods, a few manuscripts focused instead on developing Conceptual models of interrelated notions of spatial scale. For example, Pereira (2002) put forth a typology of scale relations ${ }^{17}$ based on the comparison of the grain (i.e., observation scales) and extent (i.e., geographic scales) of two different hypothetical scales. The typology provides seven possible relationships, though there is limited discussion on how they are used practically, which relations are most common, or the appropriateness of the relations for describing (empirical) data versus (theoretical) processes. Another example proposes The Scale Matcher, which provides an ontology for describing the relationships between issues of precision, accuracy, and geographic scale between the available data, the expected input to a model, and the phenomena being modeled (Lilburne et al., 2004). Similarly, Zhang et al. (2014) develop a scale compatibility framework that considers different scale types, dimensions, and measurements. The goal of these conceptual models is to make the limits of spatial modeling more explicit to analysts and provide a mechanism to validate the scales used in an analysis, though a lack of their pervasive adoption hints towards the trend to instead rely on intuition, often allowing limitations to remain implicit.

Finally, it is worth noting some Other areas that either did not form coherent sub-topics or that seem to be under-represented in the corpus. First, there is a surprising lack of manuscripts pertaining to spatial networks, including both planar networks, where the nodes and the edges are geometric entities (i.e., street system or power grid), and non-planar networks, where the nodes are georeferenced but the edges are not (i.e., migration or retail expenditure). Planar network methods were observed in the corpus in the context of multiscale hierarchical data structures for street networks and the detection of multiscale clusters along a network (Shiode \& Shiode, 2009; Li \& Zhou, 2012). Since the observations are physical entities abstracted as nodes and edges, this removes the need for an exogenously defined observation scale, which means these examples leverage multiple geographic scales. In contrast, non-planar networks were not observed in the corpus despite the rich tradition in the geographical sciences of modeling spatial interaction and the use of scale concepts to define their spatial structure ${ }^{18}$. Second, machine learning and neural networks were only central in two manuscripts (Zhao et al., 2018; Guo \& Feng, 2018), which is counter to the rise of geospatial artificial intelligence (i.e., geoAI) and the recent explosion in deep learning ${ }^{19}$. This suggests more work is needed to develop spatially explicit AI methods that leverage spatial scale. Third, only a single example exploring the long-standing task of location-allocation (Cromley et al., 2012) may imply that spatial scale is a relatively peripheral concern for spatial optimization compared to the other

\footnotetext{
${ }^{17}$ Pereira (2002) actually looks at spatial, temporal, and spatial-temporal scale relations.

${ }^{18}$ See Oshan (2020) for an overview.

${ }^{19}$ For example, see Janowicz et al. (2019).
} 
tasks described here perhaps because the focus is instead on an exogenously defined objective function and optimality criterion, rather on than a particular process ${ }^{20}$.

\section{Scale multiplicity and the inference of spatial processes}

In this section, the trends from the scoping review are further distilled in order to formalize a typology of how scale is used for different tasks (blue box in Figure 1). This predominantly entails categorizing tasks and specific methods in terms of the notions of scale that are employed, whether they are cross-scale or multiscale, and if the focus is on data, measurement, or inference. In addition, methods are distinguished as endogenous or exogenous depending on whether the scales were explicitly predefined (exogenous) or extracted from a system based on a criterion (endogenous).

Most quantitative geographic research relies upon the specification of at least one geographic scale (i.e., exent) and one observation scale (i.e., units or objects), either implicitly or explicitly, to facilitate data collection and analysis. However, at a single scale, the amount of information that can be obtained about process scale is limited. It is the shift from one scale to multiple scales that enables the scale of processes to be brought into focus. Furthermore, though it is straightforward to theorize about the scale of a process, such a scale often cannot be directly observed. This means that to learn about process scale, it is necessary to rely on inference, which requires data at multiple measurable scales (i.e., geographic scale or observation scale). Figure 2 illustrates the mode of inquiry whereby data are observed and collected in order to measure associations that ultimately allow inferences to be made. This diagram was previously used by Fotheringham (2020) to discuss how data are used to inform on the properties of spatial processes (i.e., quality and magnitude), which are dependent on scale. Therefore, the diagram is modified here to incorporate the role of scale at each stage of the diagram and to describe how data at multiple scales allow inferences to be made about the scale of processes (i.e., local versus global or higher-level versus lower-level) in addition to the quality and magnitude of processes.

The box in the top left of Figure 2 represents the sub-topics and tasks identified through the scoping review that are predominately about spatial data handling (i.e., storage, integration,

\footnotetext{
${ }^{20}$ Instead of the issue of scale, the focus of location-allocation and spatial optimization appear to center on the related issues of data aggregation and zone definition, of which there are several examples in GEAN (e.g., Goodchild, 1979; Current \& Schilling, 1990; Fotheringham et al., 1995; Murray \& Gottsegen, 1997; Francis et al., 1999).
} 
viewing, accessing, and feature engineering), which were central to the Cartography \& GIS and Remote Sensing \& Image processing categories. Here, scale plays the role of moderating how observations are semantically related to one another. Data observed at similar cartographic, geographic or observation scales are anticipated to be related (possibly to the point of being redundant) whereas data observed at different scales are more likely to be unrelated. Moreover, the focus in this context is typically on multiscale methods with the objective of facilitating the integration of spatial information for downstream consumption (i.e, classification, regression, simulation).

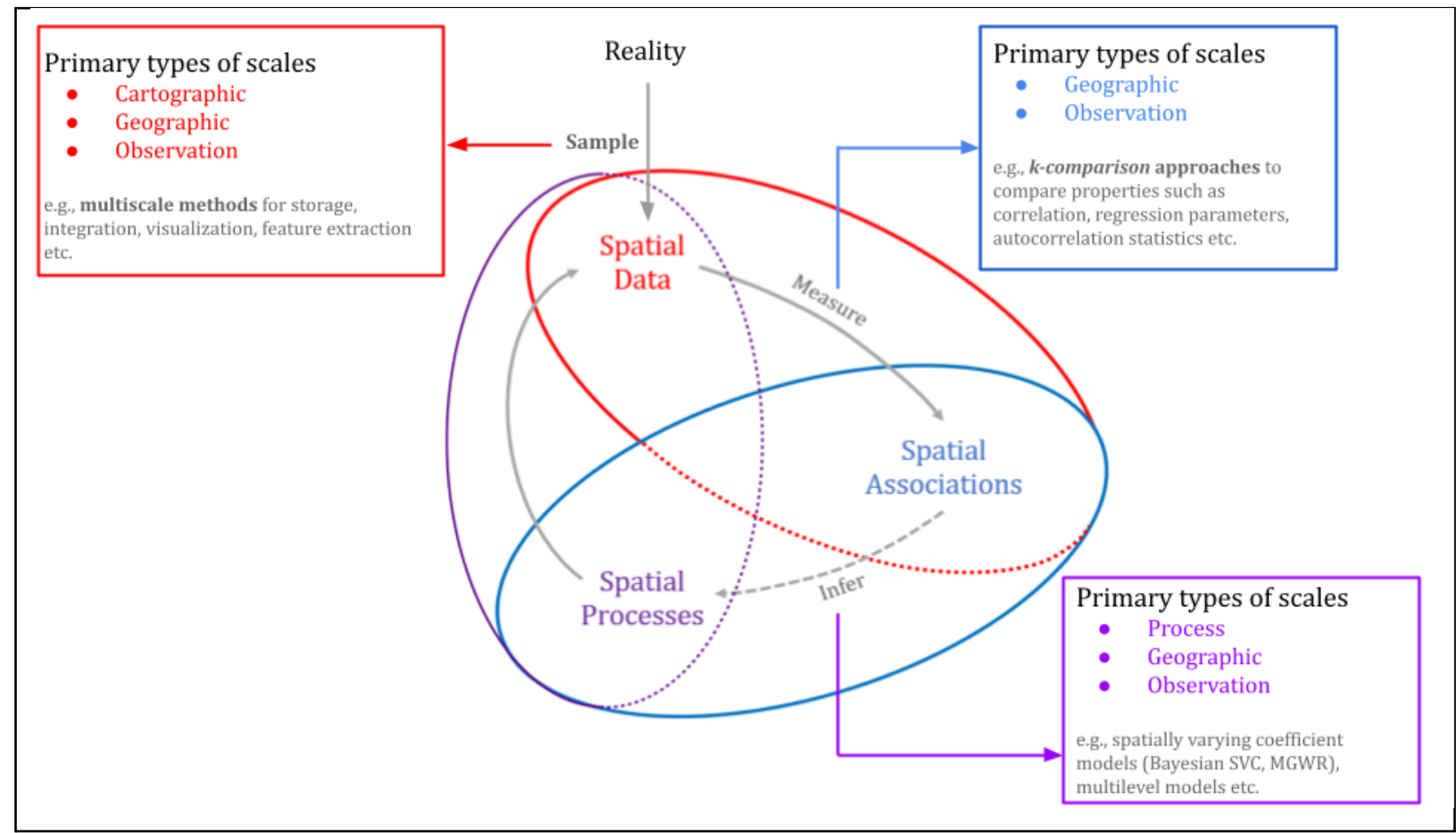

Figure 2: The relationship between the multiple scales of spatial data and spatial processes and the tasks and methods that are most closely related with them.

In contrast, the boxes on the right focus on using data measured at multiple geographic or observation scales to inform about process scale(s). The top box can be further differentiated by tasks that compare associations at multiple scales using exogenous cross-scale techniques. This covers most profiling techniques, clustering methods, explorations of the MAUP, or verifications of scaling properties, and includes cases where either multiple geographic scales or multiple observation scales are used. As a result, the common label of $k$-comparison methods is appropriate for any task looking to informally quantify process scale through the juxtaposition of results obtained at $k$ pre-specified realizations of scale. The majority of examples $\left(\sim \frac{1}{3}\right)$ from the corpus of literature used a $k$-comparison approach to analyze changes in metrics, such as correlation coefficients, indices, spatial autocorrelation statistics, simulations or regression parameters (e.g., Parker et al., 2001; Nelson et al., 2007; Southworth 
et al., 2006; Elliott and Kipfmueller, 2011; Kim et al., 2012; Perveen and James, 2011; Patterson and Doyle, 2011; Wright et al., 2013; Zhang et al., 2013; Jacobs-Crisioni et al., 2014; Bao and Tong, 2017; Fernandez and Wu, 2016; Liu et al., 2017; Carr et al., 2019; Li et al., 2019 and many more ${ }^{21}$ ). It is important to recognize that even though $k$-comparison methods may include inferences on processes (i.e., their quality and magnitude) they do not typically provide explicit inferences on the scale(s) of processes. That is, they do not inform us about how appropriate a particular scale is nor do they express uncertainty about the scales under consideration.

The final box at the bottom of Figure 2 contains the tasks and methods that provide explicit information about process scale(s) through more formal inference. The first example in this group is GWR from the decomposition sub-topic, which searches across geographic scales to make cross-scale comparisons and endogenously selects a bandwidth that is an indicator (i.e., extent) of process scale. As already mentioned, GWR has been extended to MGWR which provides an indicator (i.e., extent) of process scale for each relationship in a model. MGWR achieves this by making a series of simultaneous cross-scale searches across geographic scales. Therefore, MGWR is a multiscale method in that it combines and extracts information regarding multiple process scales. There were many examples of GWR in the corpus (e.g., Gao and Li, 2011; Miller and Hanham, 2011; Propastin, 2011; Su et al., 2012; Pearsall and Christman, 2012; Rennermalm et al., 2012; Brown, 2017; Li et al., 2017; Jendryke and McClure, 2019; Hazell \& Rinner, 2019) and because of its novelty, there were fewer examples using MGWR (Fotheringham et al., 2017; Wolf et al., 2018; Murakami et al., 2019; Bilgel, 2020; Shabrina et al., 2021; Forati \& Gose, 2021; Fotheringham et al., 2021), though the number was increasing in recent years, along with methodological enhancements and computational improvements (Wu et al., 2019c; Yu et al., 2020; Li \& Fotheringham, 2020; Zhang et al., 2021; Hagenauer \& Helbich, 2021; Wu et al., 2021a; Wu et al., 2021b). A second example of a model form that falls into this box is that of multilevel models, which are also found in the decomposition sub-topic. Since traditional multilevel models always incorporate multiple exogenously defined observation scales, they allow inferences to be made about the levels where one or more processes can be explained. There were several examples of traditional multilevel models in the corpus (e.g., Barnett, 1973; Duncan \& Jones, 2000; Kolaczyk and Huang, 2000; Dong and Harris, 2015; Manley et al., 2015; Tian et al., 2015; Johnston et al., 2016; Malanson et al., 2017; Ma et al., 2018; Greene and Kedron, 2018; Sun \&

\footnotetext{
${ }^{21}$ For readability, additional examples of $k$-comparison approaches from the corpus are listed here: (Phillips, 1986; Band, 1989; Bian \& Walsh, 1993; Stoms, 1994; Jantz \& Goetz, 2005; Kwan \& Weber, 2008; Mountrakis \& Gunson, 2009; Verfaillie et al., 2009; Pontius et al., 2011; Yamada et al., 2012; Root, 2012; Giraldo, 2012; Ma et al., 2012; McClintock, 2012; Zhang et al., 2013; Kim, 2013; Aguilera-Benavente et al., 2014; Houston, 2014; Mateo Sánchez et al., 2014; Clark et al., 2015; Weiss et al., 2015; Barnes et al., 2016; Cabrera-Barona et al., 2016; He et al., 2017; Rendenieks et al., 2017; Li et al., 2018; Bagstad et al., 2018; Cebrecos et al., 2018; Vu et al., 2018; Hazell \& Rinner, 2019; Wu et al., 2019b; Salvati et al., 2020; Doeffinger \& Hall, 2021)
} 
Yin, 2018; Manley et al., 2019), but few instances of multilevel models extended to become analogous to GWR and MGWR (i.e., spatially varying coefficient models) by searching across geographic scales (i.e., ranges) to allow process scale(s) to be expressed endogenously. The final examples in this box include techniques for calculating summaries across exogenously defined scales. Recall that Petrović et al. (2018) computed the entropy for values measured for a series of geographic scales and that Burden and Steel (2016) computed distributions of regression coefficients resulting from the MAUP. Though these both present straightforward means of moving from cross-scale techniques to multiscale techniques to learn about the characteristics of processes (i.e., complexity or uncertainty) they were not featured prominently in the corpus nor do they explicitly measure the complexity or uncertainty of process scale, suggesting important directions for future work.

\section{Summary}

This paper highlights how the concept of spatial scale is used in the geographical sciences by providing an overview of previous conceptualizations of scale and then undertaking a scoping review on the topic. From this, we describe and classify tasks and methods that use scale in the literature, leading to an expanded understanding of the role of different notions of scales (type I scale multiplicity) and the simultaneous use of multiple scales (type II scale multiplicity). Previous reviews on the topic of spatial scale do not differentiate between different types of scale multiplicity and typically focus on type I scale multiplicity rather than type II scale multiplicity. In contrast, this review included a substantial focus on type II scale multiplicity, illuminating the need to distinguish the characteristics of both types of scale multiplicity when discussing spatial analytical methods. The main outcome is a categorization of the primary modes of inquiry through the lens of multiple scales for handling spatial data, measuring associations, and inferring unmeasurable processes. Another outcome is the finding that methods capable of making explicitly multiscale inferences about the scale of processes were less abundant in the literature than methods that informally examined process scale. The results of this study therefore suggest that more work is needed to formalize multiscale inferential techniques and reasoning associated with process scale when developing and applying quantitative geographic workflows. For example, initial efforts have been made to explore the uncertainty of process scale measurement (Stuber et al., 2017; Wolf et al., $2018 \mathrm{Li}$ et al., 2020), to understand the MAUP in terms of the properties of spatial processes rather than the properties of spatial data (Fotheringham \& Sachdeva, 2022), and no method yet provides location-specific inferences on process scale (Oshan et al., 2020; Fotheringham 2020). The development of frameworks for incorporating multiscale representations into GeoAI and deep learning algorithms (e.g., Guo \& Feng, 2018; Zhao et al., 2018; Janowicz et al., 2019) is another burgeoning area of research that is important for the development of the field. These 
advances will allow us to better understand the spatial processes that generate the patterns we experience and to more accurately and efficiently characterize spatial relationships.

There are also a number of steps that can help accelerate the development of a more unified theory of spatial scale and the scientific inquiries that depend on such a theoretical framework. One step would be to adopt a standardized reporting guideline for geographic research, such as the STROBE initiative for reporting observational studies in epidemiology (Elm et al., 2007; Vandenbroucke et al., 2014), which aims to promote the adequate dissemination of research through collaboratively compiled checklists. A similar mechanism could be developed by geographical scientists in conjunction with domain specialists to suggest a minimal set of criteria for adequately differentiating the many types and uses of spatial scale. This could help further alleviate existing ambiguities about scale and stem future ones, as well as make similar types of research more discoverable. It could also have positive ramifications for reproducibility and replicability in the geographical sciences, given the acknowledgement that findings may not be generalizable at different scales and spatial contexts (Kedron et al., 2021; Goodchild \& Li, 2021). Another step forward could entail a series of more systematic reviews that complement this scoping review in order to further explore individual categories identified here or how particular spatial multiscale analytical methods are used across disciplines. Finally, this review could be expanded to increase the number of manuscripts in the corpus by including additional journals, such as those targeting specific disciplines. These steps would likely stimulate more work that directs attention toward addressing the feasibility and effectiveness of techniques for quantitatively measuring aspects of spatial scale and its role in understanding our world. 


\section{References (not from corpus)}

1. Allen, T. F. H., \& Starr, T. B. (2017). Hierarchy: Perspectives for Ecological Complexity. In Hierarchy. University of Chicago Press.

2. Anselin, L. (1995). Local Indicators of Spatial Association-LISA. Geographical Analysis, 27(2), 93-115.

3. Arbia, G. (1989). Spatial Data Configuration in Statistical Analysis of Regional Economic and Related Problems. Springer Netherlands.

4. Arksey, H., \& O’Malley, L. (2005). Scoping studies: Towards a methodological framework. International Journal of Social Research Methodology, 8(1), 19-32.

5. Batty, M., Longley, P., \& Fotheringham, S. (1989). Urban growth and form: Scaling, fractal geometry, and diffusion-limited aggregation. Environment and Planning A, $21(11), 1447-1472$.

6. Brunsdon, C., Fotheringham, A. S., \& Charlton, M. E. (1996). Geographically weighted regression: A method for exploring spatial nonstationarity. Geographical Analysis, 28(4), 281-298.

7. Csillag, F., Fortin, M.-J., \& Dungan, J. L. (2000). On the Limits and Extensions of the Definition of Scale. On the Limits and Extensions of the Definition of Scale, 81(3), 230-232.

8. Current, J. R., \& Schilling, D. A. (1990). Analysis of Errors Due to Demand Data Aggregation in the Set Covering and Maximal Covering Location Problems. Geographical Analysis, 22(2), 116-126.

9. Dabiri, Z., \& Blaschke, T. (2019). Scale matters: A survey of the concepts of scale used in spatial disciplines. European Journal of Remote Sensing, 52(1), 419-434.

10. Dark, S. J., \& Bram, D. (2007). The modifiable areal unit problem (MAUP) in physical geography. Progress in Physical Geography: Earth and Environment, 31(5), 471-479.

11. Dungan, J. L., Perry, J. N., Dale, M. R. T., Legendre, P., Citron-Pousty, S., Fortin, M.-J., Jakomulska, A., Miriti, M., \& Rosenberg, M. S. (2002). A balanced view of scale in spatial statistical analysis. Ecography, 25(5), 626-640.

12. Duque, J. C., Ramos, R., \& Suriñach, J. (2007). Supervised Regionalization Methods: A Survey. International Regional Science Review, 30(3), 195-220. 
13. Elm, E. von, Altman, D. G., Egger, M., Pocock, S. J., Gøtzsche, P. C., \& Vandenbroucke, J. P. (2007). Strengthening the reporting of observational studies in epidemiology (STROBE) statement: Guidelines for reporting observational studies. $B M J, 335(7624), 806-808$.

14. Fotheringham, A. S., \& Wong, D. W. S. (1991). The modifiable areal unit problem in multivariate statistical analyses. Environment and Planning A, 23, 1025-1044.

15. Fotheringham, A. S., Densham, P. J., \& Curtis, A. (1995). The Zone Definition Problem in Location-Allocation Modeling. Geographical Analysis, 27(1), 60-77.

16. Fotheringham, A. S., Charlton, M. E., \& Brunsdon, C. (1998). Geographically weighted regression: A natural evolution of the expansion method for spatial data analysis. Environment and Planning A, 30(11), 1905 - 1927.

17. Fotheringham, A. S., Brunsdon, C., \& Charlton, M. (2002). Geographically Weighted Regression: The Analysis of Spatially Varying Relationships. John Wiley \& Sons.

18. Fotheringham, A. S. (2020). Local modeling: One size does not fit all. Journal of Spatial Information Science, 2020(21), 83-87.

19. Fotheringham, A. S., \& Sachdeva, M. (2022). Scale and local modeling: New perspectives on the modifiable areal unit problem and Simpson's paradox. Journal of Geographical Systems.

20. Fowler, C. (2016). Segregation as a multiscalar phenomenon and its implications for neighborhood-scale research: The case of South Seattle 1990-2010. Urban Geography, $37(1), 1-25$.

21. Getis, A., \& Ord, J. K. (1992). The Analysis of Spatial Association by Use of Distance Statistics. Geographical Analysis, 24(3), 189-206.

22. Gibson, C. C., Ostrom, E., \& Ahn, T. K. (2000). The concept of scale and the human dimensions of global change: A survey. Ecological Economics, 32(2), 217-239.

23. Goldstein, H., Browne, W., \& Rabash, J. (2002). Partitioning variation in multilevel models. Understanding statistics: statistical issues in psychology, education, and the social sciences 1 (4), 223-231

24. Goodchild, M. F. (1979). The Aggregation Problem in Location-Allocation. Geographical Analysis, 11(3), 240-255.

25. Goodchild, M. F. (2001). Metrics of scale in remote sensing and GIS. International Journal of Applied Earth Observation and Geoinformation, 3(2), 114-120. 
26. Goodchild, M. F., \& Li, W. (2021). Replication across space and time must be weak in the social and environmental sciences. Proceedings of the National Academy of Sciences, 118(35).

27. Harvey, D. W. (1968). Pattern, Process, and the Scale Problem in Geographical Research. Transactions of the Institute of British Geographers, 45, 71.

28. Hipp, J. R., \& Boessen, A. (2013). Egohoods As Waves Washing Across The City: A New Measure Of "Neighborhoods". Criminology, 51(2), 287-327.

29. Jelinski, D. E., \& Wu, J. (1996). The modifiable areal unit problem and implications for landscape ecology. Landscape Ecology, 11(3), 129-140.

30. Jenerette, D., \& Wu, J. (2000). On the Definitions of Scale. Bulletin of the Ecological Society of America, 81(1), 104-105.

31. Jenerette, G. D., \& Wu, J. (2010). Quantitative Measures and Ecological Hierarchy. In L. A. Kapustka \& W. G. Landis (Eds.), Environmental Risk Assessment and Management from a Landscape Perspective (pp. 75-95). John Wiley \& Sons, Inc.

32. Jiang, B., \& Brandt, S. (2016). A Fractal Perspective on Scale in Geography. ISPRS International Journal of Geo-Information, 5(6), 95.

33. Johnston, R., Manley, D., \& Jones, K. (2018). Spatial scale and measuring segregation: Illustrated by the formation of Chicago's ghetto. GeoJournal, 83(1), 73-85.

34. Khalil, H., Peters, M., Godfrey, C. M., McInerney, P., Soares, C. B., \& Parker, D. (2016). An Evidence-Based Approach to Scoping Reviews: EBP Approach to Scoping Reviews. Worldviews on Evidence-Based Nursing, 13(2), 118-123.

35. Kopf, J., Shamir, A., \& Peers, P. (2013) Content-adaptive image downscaling. ACM Transactions on Graphics (TOG) 32 (6), 1-8.

36. Levac, D., Colquhoun, H., \& O’Brien, K. K. (2010). Scoping studies: Advancing the methodology. Implementation Science, 5(1), 69.

37. Manson, S. M. (2008). Does scale exist? An epistemological scale continuum for complex human-environment systems. Geoforum, 39(2), 776-788.

38. Marceau, D. J. (1999). The scale issue in social and natural sciences. Canadian Journal of Remote Sens, 25(4), 18.

39. Marceau, D. J., \& Hay, G. J. (1999). Remote Sensing Contributions to the Scale Issue. Canadian Journal of Remote Sensing, 25(4), 357-366. 
40. Meentemeyer, V. (1989). Geographical perspectives of space, time, and scale. Landscape Ecology, 3(3-4), 163-173.

41. Munn, Z., Peters, M. D. J., Stern, C., Tufanaru, C., McArthur, A., \& Aromataris, E. (2018). Systematic review or scoping review? Guidance for authors when choosing between a systematic or scoping review approach. BMC Medical Research Methodology, 18(1), 143.

42. Murray, A. T., \& Gottsegen, J. M. (1997). The Influence of Data Aggregation on the Stability of p-Median Location Model Solutions. Geographical Analysis, 29(3), 200-213.

43. O’Neill, R. V., \& Smith, M. A. (2002). Scale and Hierarchy Theory. In S. E. Gergel \& M. G. Turner (Eds.), Learning Landscape Ecology: A Practical Guide to Concepts and Techniques (pp. 1-8). Springer.

44. Openshaw, S., \& Taylor, P. J. (1979). A million or so correlation coefficients: Three experiments on the modifiable areal unit problem. Statistical Applications in the Spatial Sciences.

45. Oshan, T., Li, Z., Kang, W., Wolf, L., \& Fotheringham, A. (2019). mgwr: A Python Implementation of Multiscale Geographically Weighted Regression for Investigating Process Spatial Heterogeneity and Scale. ISPRS International Journal of Geo-Information, 8(6), 269.

46. Oshan, T. M. (2020). The spatial structure debate in spatial interaction modeling: 50 years on. Progress in Human Geography, 0309132520968134.

47. Oshan, T. M., Smith, J. P., \& Fotheringham, A. S. (2020). Targeting the spatial context of obesity determinants via multiscale geographically weighted regression. International Journal of Health Geographics, 19(1), 11.

48. Peters, M. D. J., Godfrey, C. M., Khalil, H., McInerney, P., Parker, D., \& Soares, C. B. (2015). Guidance for conducting systematic scoping reviews: International Journal of Evidence-Based Healthcare, 13(3), 141-146.

49. Pham, M. T., Rajić, A., Greig, J. D., Sargeant, J. M., Papadopoulos, A., \& McEwen, S. A. (2014). A scoping review of scoping reviews: Advancing the approach and enhancing the consistency. Research Synthesis Methods, 5(4), 371-385.

50. Quattrochi, D. A., \& Goodchild, M. F. (Eds.). (1997). Scale in Remote Sensing and GIS (1 edition). CRC Press. 
51. Ruddell, D., \& Wentz, E. A. (2009). Multi-Tasking: Scale in Geography. Geography Compass, 3(2), 681-697.

52. Sheppard, E. S., \& McMaster, R. B. (2004). Scale and Geographic Inquiry: Nature, Society, and Method. Blackwell.

53. Silbernagel, J. (1997). Scale Perception: From Cartography to Ecology. Bulletin of the Ecological Society of America, 78(2), 166-169.

54. Stuber, E. F., Gruber, L. F., \& Fontaine, J. J. (2017). A Bayesian method for assessing multi-scale species-habitat relationships. Landscape Ecology, 32(12), 2365-2381.

55. Stuber, E. F., \& Gruber, L. F. (2020). Recent Methodological Solutions to Identifying Scales of Effect in Multi-scale Modeling. Current Landscape Ecology Reports.

56. Sun, W., Xu, G., Gong, P., \& Liang, S. (2006). Fractal analysis of remotely sensed images: A review of methods and applications. International Journal of Remote Sensing, 27(22), 4963-4990.

57. Tricco, A. C., Lillie, E., Zarin, W., O’Brien, K. K., Colquhoun, H., Levac, D., Moher, D., Peters, M. D. J., Horsley, T., Weeks, L., Hempel, S., Akl, E. A., Chang, C., McGowan, J., Stewart, L., Hartling, L., Aldcroft, A., Wilson, M. G., Garritty, C., ... Straus, S. E. (2018). PRISMA Extension for Scoping Reviews (PRISMA-ScR): Checklist and Explanation. Annals of Internal Medicine, 169(7), 467-473.

58. Turner, M. G. (1989). Landscape Ecology: The Effect of Pattern on Process. Annual Review of Ecology and Systematics, 29.

59. Vandenbroucke, J. P., von Elm, E., Altman, D. G., Gøtzsche, P. C., Mulrow, C. D., Pocock, S. J., Poole, C., Schlesselman, J. J., Egger, M., \& STROBE Initiative. (2014). Strengthening the Reporting of Observational Studies in Epidemiology (STROBE): Explanation and elaboration. International Journal of Surgery (London, England), 12(12), 1500-1524.

60. Wolf, L. J., Fox, S., Harris, R., Johnston, R., Jones, K., Manley, D., Tranos, E., \& Wang, W. W. (2020). Quantitative geography III: Future challenges and challenging futures. Progress in Human Geography, 030913252092472.

61. Wu, J., \& Li, H. (2006). Concepts Of Scale And Scaling. In Scaling And Uncertainty Analysis In Ecology (p. 13). Springer.

62. Wu, H., \& Li, Z.-L. (2009). Scale Issues in Remote Sensing: A Review on Analysis, Processing and Modeling. Sensors, 9(3), 1768-1793. 
63. Wu, J. (2013). Hierarchy Theory: An Overview. In R. Rozzi, S. T. A. Pickett, C. Palmer, J. J. Armesto, \& J. B. Callicott (Eds.), Linking Ecology and Ethics for a Changing World: Values, Philosophy, and Action (pp. 281-301). Springer Netherlands.

\section{References (from corpus)}

1. Aguilera-Benavente, F., Botequilha-Leitão, A., \& Díaz-Varela, E. (2014). Detecting multi-scale urban growth patterns and processes in the Algarve region (Southern Portugal). Applied Geography, 53, 234-245.

2. An, L., Linderman, M., Qi, J., Shortridge, A., \& Liu, J. (2005). Exploring Complexity in a Human-Environment System: An Agent-Based Spatial Model for Multidisciplinary and Multiscale Integration. Annals of the Association of American Geographers, 95(1), 54-79.

3. Appleby, S. (1996). Multifractal Characterization of the Distribution Pattern of the Human Population. Geographical Analysis, 28(2), 147-160.

4. Argyridis, A., \& Argialas, D. (2019). Fuzzy ontology-based foreshore identification from digital terrain models and very high-resolution airborne imagery through GEOBIA multi-scale analysis. International Journal of Geographical Information Science, 33(11), 2153-2169.

5. Atkinson, P. M., \& Tate, N. J. (2000). Spatial Scale Problems and Geostatistical Solutions: A Review. The Professional Geographer, 52(4), 607-623.

6. Bagstad, K. J., Cohen, E., Ancona, Z. H., McNulty, S. G., \& Sun, G. (2018). The sensitivity of ecosystem service models to choices of input data and spatial resolution. Applied Geography, 93, 25-36.

7. Baker, W. L. (1989). Macro- and Micro-scale Influences on Riparian Vegetation in Western Colorado. Annals of the Association of American Geographers, 79(1), 65-78.

8. Band, L. E. (1989). Spatial Aggregation of Complex Terrain. Geographical Analysis, 21(4), 279-293.

9. Barnes, T. L., Colabianchi, N., Hibbert, J. D., Porter, D. E., Lawson, A. B., \& Liese, A. D. (2016). Scale effects in food environment research: Implications from assessing socioeconomic dimensions of supermarket accessibility in an eight-county region of South Carolina. Applied Geography, 68, 20-27. 
10. Bao, K. Y., \& Tong, D. (2017). The Effects of Spatial Scale and Aggregation on Food Access Assessment: A Case Study of Tucson, Arizona. The Professional Geographer, 69(3), 337-347.

11. Barnett, J. R. (2010). Scale Components in the Diffusion of the Danish Communist Party, 1920-64*. Geographical Analysis, 5(1), 35-44.

12. Batty, M. (2010). Space and Scale in Entropy Maximizing. Geographical Analysis, $42(4), 395-421$.

13. Bednarz, R., \& Ralston, B. (1982). THE IMPORTANCE OF SCALE IN MEASURING THE SECONDARY EFFECTS IN REGRESSION ANALYSIS. The Professional Geographer, 34(4), 424-431.

14. Bendix, J. (1994). Scale, Direction, and Pattern in Riparian Vegetation-Environment Relationships. Annals of the Association of American Geographers, 84(4), 652-665.

15. Bian, L., \& Walsh, S. J. (1993). Scale dependencies of vegetation and topography in a mountainous environment of Montana. Professional Geographer, 45(1), 1.

16. Bilgel, F. (2020). Guns and Homicides: A Multiscale Geographically Weighted Instrumental Variables Approach. Geographical Analysis, 52(4), 588-616.

17. Bonnell, T. R., Chapman, C. A., \& Sengupta, R. (2016). Interaction between scale and scheduling choices in simulations of spatial agents. International Journal of Geographical Information Science, 1-14.

18. Boots, B., \& Okabe, A. (2007). Local statistical spatial analysis: Inventory and prospect. International Journal of Geographical Information Science, 21(4), 355-375.

19. Borda-Niño, M., Hernández-Muciño, D., \& Ceccon, E. (2017). Planning restoration in human-modified landscapes: New insights linking different scales. Applied Geography, $83,118-129$.

20. Brown, I. (2017). Hierarchical bioclimate zonation to reference climate change across scales and its implications for nature conservation planning. Applied Geography, 85, $126-138$.

21. Buck, K. D. (2017). A Proposed Method for Spatial Data Disaggregation and Interpolation. The Professional Geographer, 69(1), 70-79.

22. Burden, S., \& Steel, D. (2016). Empirical Zoning Distributions for Small Area Data: Empirical Zoning Distributions. Geographical Analysis, 48(4), 373-390. 
23. Cabrera-Barona, P., Wei, C., \& Hagenlocher, M. (2016). Multiscale evaluation of an urban deprivation index: Implications for quality of life and healthcare accessibility planning. Applied Geography, 70, 1-10.

24. Carr, J. K., Fontanella, S. A., \& Tribby, C. P. (2019). Identifying American Beer Geographies: A Multiscale Core-Cluster Analysis of U.S. Breweries. The Professional Geographer, 71(2), 185-196.

25. Cebrecos, A., Domínguez-Berjón, M. F., Duque, I., Franco, M., \& Escobar, F. (2018). Geographic and statistic stability of deprivation aggregated measures at different spatial units in health research. Applied Geography, 95, 9-18.

26. Chapa-Vargas, L., \& Monzalvo-Santos, K. (2012). Natural protected areas of San Luis Potosí, Mexico: Ecological representativeness, risks, and conservation implications across scales. International Journal of Geographical Information Science, 26(9), $1625-1641$.

27. Chen, G., Hay, G. J., Castilla, G., St-Onge, B., \& Powers, R. (2011). A multiscale geographic object-based image analysis to estimate lidar-measured forest canopy height using Quickbird imagery. International Journal of Geographical Information Science, 25(6), 877-893.

28. Chen, Y., \& Zhou, Q. (2013). A scale-adaptive DEM for multi-scale terrain analysis. International Journal of Geographical Information Science, 27(7), 1329-1348.

29. Chou, Y. H. (1991). Map Resolution and Spatial Autocorrelation. Geographical Analysis, 23(3), 228-246.

30. Christian, B. A., Dhinwa, P. S., \& Ajai. (2018). Long term monitoring and assessment of desertification processes using medium \& high resolution satellite data. Applied Geography, 97, 10-24.

31. Clark, W. A. V., Anderson, E., Östh, J., \& Malmberg, B. (2015). A Multiscalar Analysis of Neighborhood Composition in Los Angeles, 2000-2010: A Location-Based Approach to Segregation and Diversity. Annals of the Association of American Geographers, 105(6), 1260-1284.

32. Clarke, K. C. (2016). A multiscale masking method for point geographic data. International Journal of Geographical Information Science, 30(2), 300-315.

33. Cola, L. D. (1994). Simulating and mapping spatial complexity using multi-scale techniques. International Journal of Geographical Information Systems, 8(5), 411-427. 
34. Collins, J. B., \& Woodcock, C. E. (2000). Combining Geostatistical Methods and Hierarchical Scene Models for Analysis of Multiscale Variation in Spatial Data. Geographical Analysis, 32(1), 50-63.

35. Cromley, R. G., Lin, J., \& Merwin, D. A. (2012). Evaluating representation and scale error in the maximal covering location problem using GIS and intelligent areal interpolation. International Journal of Geographical Information Science, 26(3), 495-517.

36. De Cola, L. (1994). Simulating and mapping spatial complexity using multi-scale techniques. International Journal of Geographical Information Systems, 8(5), 411-427.

37. Dekavalla, M., \& Argialas, D. (2017). Evaluation of a spatially adaptive approach for land surface classification from digital elevation models. International Journal of Geographical Information Science, 31(10), 1978-2000.

38. Deng, Y., \& Wilson, J. P. (2008). Multi-scale and multi-criteria mapping of mountain peaks as fuzzy entities. International Journal of Geographical Information Science, 22(2), 205-218.

39. Doeffinger, T., \& Hall, J. W. (2021). Assessing water security across scales: A case study of the United States. Applied Geography, 134, 102500.

40. Dong, G., \& Harris, R. (2015). Spatial Autoregressive Models for Geographically Hierarchical Data Structures: Hierarchical Spatial Autoregressive Models. Geographical Analysis, 47(2), 173-191.

41. Dong, G., Ma, J., Lee, D., Chen, M., Pryce, G., \& Chen, Y. (2020). Developing a Locally Adaptive Spatial Multilevel Logistic Model to Analyze Ecological Effects on Health Using Individual Census Records. Annals of the American Association of Geographers, 110(3), 739-757.

42. Drăguţ, L., Tiede, D., \& Levick, S. R. (2010). ESP: A tool to estimate scale parameter for multiresolution image segmentation of remotely sensed data. International Journal of Geographical Information Science, 24(6), 859-871.

43. Du, S., Guo, L., \& Wang, Q. (2010). A scale-explicit model for checking directional consistency in multi-resolution spatial data. International Journal of Geographical Information Science, 24(3), 465-485.

44. Du, S., Wang, Q., \& Guo, L. (2010). Modeling the scale dependences of topological relations between lines and regions induced by reduction of attributes. International Journal of Geographical Information Science, 24(11), 1649-1686. 
45. Duncan, C., \& Jones, K. (2000). Using Multilevel Models to Model Heterogeneity: Potential and Pitfalls. Geographical Analysis, 32(4), 279-305.

46. Eckert, S., Giger, M., \& Messerli, P. (2016). Contextualizing local-scale point sample data using global-scale spatial datasets: Lessons learnt from the analysis of large-scale land acquisitions. Applied Geography, 68, 84-94.

47. Elliott, G. P., \& Kipfmueller, K. F. (2011). Multiscale Influences of Climate on Upper Treeline Dynamics in the Southern Rocky Mountains, USA: Evidence of Intraregional Variability and Bioclimatic Thresholds in Response to Twentieth-Century Warming. Annals of the Association of American Geographers, 101(6), 1181-1203.

48. Fernández, I. C., \& Wu, J. (2016). Assessing environmental inequalities in the city of Santiago (Chile) with a hierarchical multiscale approach. Applied Geography, 74, 160-169.

49. Forati, A. M., \& Ghose, R. (2021). Geospatial analysis of misinformation in COVID-19 related tweets. Applied Geography, 133, 102473.

50. Fotheringham, A. S., Yang, W., \& Kang, W. (2017). Multi-Scale Geographically Weighted Regression. Annals of the American Association of Geographers, 107(6), $1247-1265$.

51. Fotheringham, A.S., Li, Z., \& Wolf, L. J. (2021). Scale, Context, and Heterogeneity: A Spatial Analytical Perspective on the 2016 U.S. Presidential Election. Annals of the American Association of Geographers, 1-20.

52. Francis, R. L., Lowe, T. J., Rushton, G., \& Rayco, M. B. (1999). A Synthesis of Aggregation Methods for Multifacility Location Problems: Strategies for Containing Error. Geographical Analysis, 31(1), 67-87.

53. Fowler, C. S., Frey, N., Folch, D. C., Nagle, N., \& Spielman, S. (2020). Who are the People in my Neighborhood?: The "Contextual Fallacy" of Measuring Individual Context with Census Geographies. Geographical Analysis, 52(2), 155-168.

54. Gao, J., \& Li, S. (2011). Detecting spatially non-stationary and scale-dependent relationships between urban landscape fragmentation and related factors using Geographically Weighted Regression. Applied Geography, 31(1), 292-302.

55. Giraldo, M. A. (2012). Spatial scale and land use fragmentation in monitoring water processes in the Colombian Andes. Applied Geography, 34, 395-402.

56. Goodchild, M. F., \& Mark, D. M. (1987). The Fractal Nature of Geographic Phenomena. Annals of the Association of American Geographers, 77(2), 265-278. 
57. Goovaerts, P., Jacquez, G. M., \& Greiling, D. (2005). Exploring Scale-Dependent Correlations Between Cancer Mortality Rates Using Factorial Kriging and Population-Weighted Semivariograms. Geographical Analysis, 37(2), 152-182.

58. Graff, K., Lissak, C., Thiery, Y., Maquaire, O., Costa, S., Medjkane, M., \& Laignel, B. (2019). Characterization of elements at risk in the multirisk coastal context and at different spatial scales: Multi-database integration (normandy, France). Applied Geography, 111, 102076.

59. Greene, C. S., \& Kedron, P. J. (2018). Beyond fractional coverage: A multilevel approach to analyzing the impact of urban tree canopy structure on surface urban heat islands. Applied Geography, 95, 45-53.

60. Griffith, D. A. (2021). Interpreting Moran Eigenvector Maps with the Getis-Ord $\mathrm{G}_{\mathrm{i}}$ * Statistic. The Professional Geographer, 73(3), 447-463.

61. Guo, Z., \& Feng, C.-C. (2018). Using multi-scale and hierarchical deep convolutional features for 3D semantic classification of TLS point clouds. International Journal of Geographical Information Science, 1-20.

62. Hagenauer, J., \& Helbich, M. (2021). A geographically weighted artificial neural network. International Journal of Geographical Information Science, 1-21.

63. Hazell, E. C., \& Rinner, C. (2019). The impact of spatial scale: Exploring urban butterfly abundance and richness patterns using multi-criteria decision analysis and principal component analysis. International Journal of Geographical Information Science, 1-34.

64. He, S., Fang, C., \& Zhang, W. (2017). A geospatial analysis of multi-scalar regional inequality in China and in metropolitan regions. Applied Geography, 88, 199-212.

65. Hoover, B., Yaw, S., \& Middleton, R. (2019). CostMAP : an open-source software package for developing cost surfaces using a multi-scale search kernel. International Journal of Geographical Information Science, 1-19.

66. Houston, D. (2014). Implications of the modifiable areal unit problem for assessing built environment correlates of moderate and vigorous physical activity. Applied Geography, 50, 40-47.

67. Jacobs-Crisioni, C., Rietveld, P., \& Koomen, E. (2014). The impact of spatial aggregation on urban development analyses. Applied Geography, 47, 46-56.

68. Janowicz, K., Gao, S., McKenzie, G., Hu, Y., \& Bhaduri, B. (2019). GeoAI: Spatially explicit artificial intelligence techniques for geographic knowledge discovery and beyond. International Journal of Geographical Information Science, 1-12. 
69. Jantz, C. A., \& Goetz, S. J. (2005). Analysis of scale dependencies in an urban land-use-change model. International Journal of Geographical Information Science, 19(2), 217-241.

70. Jendryke, M., \& McClure, S. C. (2019). Mapping crime - Hate crimes and hate groups in the USA: A spatial analysis with gridded data. Applied Geography, 111, 102072.

71. Jiang, B., Liu, X., \& Jia, T. (2013). Scaling of Geographic Space as a Universal Rule for Map Generalization. Annals of the Association of American Geographers, 103(4), $844-855$.

72. Jiang, B. (2013). The Image of the City out of the Underlying Scaling of City Artifacts or Locations. Annals of the Association of American Geographers, 103(6), 1552-1566.

73. Jiang, B., \& Yin, J. (2014). Ht-Index for Quantifying the Fractal or Scaling Structure of Geographic Features. Annals of the Association of American Geographers, 104(3), 530-540.

74. Jiang, B. (2015). The fractal nature of maps and mapping. International Journal of Geographical Information Science, 29(1), 159-174.

75. Jiang, B., \& Ren, Z. (2019). Geographic space as a living structure for predicting human activities using big data. International Journal of Geographical Information Science, 33(4), 764-779.

76. Johnston, R., Jones, K., Burgess, S., Propper, C., Sarker, R., \& Bolster, A. (2004). Scale, Factor Analyses, and Neighborhood Effects. Geographical Analysis, 36(4), $350-368$.

77. Johnston, R., Manley, D., \& Jones, K. (2016). Spatial Polarization of Presidential Voting in the United States, 1992-2012: The "Big Sort" Revisited. Annals of the American Association of Geographers, 106(5), 1047-1062.

78. Jones, C. B. (1996). Database design for a multi-scale spatial information system. International Journal of Geographic Information Systems, 10(8).

79. Kang, J.-Y., \& Aldstadt, J. (2019). Using multiple scale spatio-temporal patterns for validating spatially explicit agent-based models. International Journal of Geographical Information Science, 33(1), 193-213.

80. Kedron, P., Frazier, A. E., Trgovac, A. B., Nelson, T., \& Fotheringham, A. S. (2021). Reproducibility and Replicability in Geographical Analysis. Geographical Analysis, 53(1), 135-147. 
81. Kelley, S. (2017). AFV refueling stations and the complexity of freeway intersections: The scale dependency of network representation. International Journal of Geographical Information Science, 31(2), 346-363.

82. Kim, D., Cairns, D. M., Bartholdy, J., \& Morgan, C. L. S. (2012). Scale-Dependent Correspondence of Floristic and Edaphic Gradients across Salt Marsh Creeks. Annals of the Association of American Geographers, 102(2), 276-294.

83. Kim, J. H. (2013). Spatiotemporal scale dependency and other sensitivities in dynamic land-use change simulations. International Journal of Geographical Information Science, 27(9), 1782-1803.

84. Kolaczyk, E. D., \& Huang, H. (2001). Multiscale Statistical Models for Hierarchical Spatial Aggregation. Geographical Analysis, 33(2), 95-118.

85. Kwan, M.-P., \& Weber, J. (2008). Scale and accessibility: Implications for the analysis of land use-travel interaction. Applied Geography, 28(2), 110-123.

86. Lam, N. S.-N., \& Quattrochi, D. A. (1992). On the Issues of Scale, Resolution, and Fractal Analysis in the Mapping Sciences*. The Professional Geographer, 44(1), $88-98$.

87. Leibovici, D. G., \& Birkin, M. H. (2015). On Geocomputational Determinants of Entropic Variations for Urban Dynamics Studies: Entropic Variations of Urban Dynamics. Geographical Analysis, 47(3), 193-218.

88. Li, Z., \& Zhou, Q. (2012). Integration of linear and areal hierarchies for continuous multi-scale representation of road networks. International Journal of Geographical Information Science, 26(5), 855-880.

89. Li, C., Li, F., Wu, Z., \& Cheng, J. (2017). Exploring spatially varying and scale-dependent relationships between soil contamination and landscape patterns using geographically weighted regression. Applied Geography, 82, 101-114.

90. Li, C., Li, J., \& Wu, J. (2018). What drives urban growth in China? A multi-scale comparative analysis. Applied Geography, 98, 43-51.

91. Li, M., Shi, X., Li, X., Ma, W., He, J., \& Liu, T. (2019). Sensitivity of disease cluster detection to spatial scales: An analysis with the spatial scan statistic method. International Journal of Geographical Information Science, 33(11), 2125-2152.

92. Li, Z., Fotheringham, A. S., Oshan, T. M., \& Wolf, L. J. (2020). Measuring Bandwidth Uncertainty in Multiscale Geographically Weighted Regression Using Akaike Weights. Annals of the American Association of Geographers, 1-21. 
93. Li, Z., \& Fotheringham, A. S. (2020). Computational improvements to multi-scale geographically weighted regression. International Journal of Geographical Information Science, 34(7), 1378-1397.

94. Liao, F. H., \& Wei, Y. D. (2015). Space, scale, and regional inequality in provincial China: A spatial filtering approach. Applied Geography, 61, 94-104.

95. Liu, H., \& Jezek, K. C. (2010). Investigating DEM Error Patterns by Directional Variograms and Fourier Analysis. Geographical Analysis, 31(3), 249-266.

96. Liu, X., Wang, Y., Li, Y., Liu, F., Shen, J., Wang, J., Xiao, R., \& Wu, J. (2017). Changes in arable land in response to township urbanization in a Chinese low hilly region: Scale effects and spatial interactions. Applied Geography, 88, 24-37.

97. Liu, X., Huang, Q., \& Gao, S. (2019). Exploring the uncertainty of activity zone detection using digital footprints with multi-scaled DBSCAN. International Journal of Geographical Information Science, 33(6), 1196-1223.

98. Liu, P., Xiao, T., Xiao, J., \& Ai, T. (2020). A multi-scale representation model of polyline based on head/tail breaks. International Journal of Geographical Information Science, 34(11), 2275-2295.

99. Lilburne, L. R., Webb, T. H., \& Benwell, G. L. (2004). The Scale Matcher: A procedure for assessing scale compatibility of spatial data and models. International Journal of Geographical Information Science, 18(3), 257-279.

100. Lloyd, C. D. (2012). Analysing the spatial scale of population concentrations by religion in Northern Ireland using global and local variograms. International Journal of Geographical Information Science, 26(1), 57-73.

101. Lloyd, C. D. (2016). Spatial scale and small area population statistics for England and Wales. International Journal of Geographical Information Science, 30(6), $1187-1206$.

102. Ma, Z., Zuckerberg, B., Porter, W. F., \& Zhang, L. (2012). Use of localized descriptive statistics for exploring the spatial pattern changes of bird species richness at multiple scales. Applied Geography, 32(2), 185-194.

103. Ma, J., Chen, Y., \& Dong, G. (2018). Flexible Spatial Multilevel Modeling of Neighborhood Satisfaction in Beijing. The Professional Geographer, 70(1), 11-21.

104. Malanson, G. P., Zimmerman, D. L., Kinney, M., \& Fagre, D. B. (2017). Relations of Alpine Plant Communities across Environmental Gradients: Multilevel versus 
Multiscale Analyses. Annals of the American Association of Geographers, 107(1), 41-53.

105. Manley, D., Johnston, R., Jones, K., \& Owen, D. (2015). Macro-, Meso- and Microscale Segregation: Modeling Changing Ethnic Residential Patterns in Auckland, New Zealand, 2001-2013. Annals of the Association of American Geographers, 105(5), 951-967.

106. Manley, D., Jones, K., \& Johnston, R. (2019). Multiscale Segregation: Multilevel Modeling of Dissimilarity — Challenging the Stylized Fact That Segregation Is Greater the Finer the Spatial Scale. The Professional Geographer, 71(3), 566-578.

107. Martin, R. D., Brabyn, L., \& Potter, M. A. (2011). Sensitivity of GIS-derived terrain variables at multiple scales for modelling stoat ( Mustela erminea ) activity. Applied Geography, 31(2), 770-779.

108. Mast, J. N., \& Chambers, C. L. (2006). Integrated Approaches, Multiple Scales: Snag Dynamics in Burned Versus Unburned Landscapes*. The Professional Geographer, 58(4), 397-405.

109. Mateo Sánchez, M. C., Cushman, S. A., \& Saura, S. (2014). Scale dependence in habitat selection: The case of the endangered brown bear ( Ursus arctos ) in the Cantabrian Range (NW Spain). International Journal of Geographical Information Science, 28(8), 1531-1546.

110. McClintock, N. (2012). Assessing soil lead contamination at multiple scales in Oakland, California: Implications for urban agriculture and environmental justice. Applied Geography, 35(1-2), 460-473.

111. Meng, X., Gao, X., Lei, J., \& Li, S. (2021). Development of a multiscale discretization method for the geographical detector model. International Journal of Geographical Information Science, 35(8), 1650-1675.

112. Miller, J. A., \& Hanham, R. Q. (2011). Spatial nonstationarity and the scale of species-environment relationships in the Mojave Desert, California, USA. International Journal of Geographical Information Science, 25(3), 423-438.

113. Mochizuki, S., \& Murakami, T. (2013). Scale dependent effects in resource selection by crop-raiding Japanese macaques in Niigata Prefecture, Japan. Applied Geography, 42, 13-22.

114. Most, M. T. (2004). Spatial Scale and Population Assignment Choices in Environmental Justice Analyses. The Professional Geographer, 56(4), 14. 
115. Moudrý, V., \& Šímová, P. (2012). Influence of positional accuracy, sample size and scale on modelling species distributions: A review. International Journal of Geographical Information Science, 26(11), 2083-2095.

116. Mountrakis, G., \& Gunson, K. (2009). Multi-scale spatiotemporal analyses of moose-vehicle collisions: A case study in northern Vermont. International Journal of Geographical Information Science, 23(11), 1389-1412.

117. Mu, L., \& Wang, F. (2008). A Scale-Space Clustering Method: Mitigating the Effect of Scale in the Analysis of Zone-Based Data. Annals of the Association of American Geographers, 98(1), 85-101.

118. Murakami, D., Lu, B., Harris, P., Brunsdon, C., Charlton, M., Nakaya, T., \& Griffith, D. A. (2019). The Importance of Scale in Spatially Varying Coefficient Modeling. Annals of the American Association of Geographers, 109(1), 50-70.

119. Nelson, A., Oberthür, T., \& Cook, S. (2007). Multi-scale correlations between topography and vegetation in a hillside catchment of Honduras. International Journal of Geographical Information Science, 21(2), 145-174.

120. Oliver, M. A., \& Webster, R. (1986). Combining Nested and Linear Sampling for Determining the Scale and Form of Spatial Variation of Regionalized Variables. Geographical Analysis, 18(3), 227-242.

121. Östh, J., Clark, W. A. V., \& Malmberg, B. (2015). Measuring the Scale of Segregation Using k -Nearest Neighbor Aggregates: Measuring the Scale of Segregation. Geographical Analysis, 47(1), 34-49.

122. Ovando-Montejo, G. A., Kedron, P., \& Frazier, A. E. (2021). Relationship between urban size and configuration: Scaling evidence from a hierarchical system in Mexico. Applied Geography, 132, 102462.

123. Parker, K. C., Parker, A. J., \& Vale, T. R. (2001). Vertebrate Feeding Guilds in California's Sierra Nevada: Relations to Environmental Condition and Change in Spatial Scale. Annals of the Association of American Geographers, 91(2), 245-262.

124. Patterson, L. A., \& Doyle, M. W. (2011). Hypsographic Demography Across Scale. The Professional Geographer, 63(4), 514-530.

125. Pearsall, H., \& Christman, Z. (2012). Tree-lined lanes or vacant lots? Evaluating non-stationarity between urban greenness and socio-economic conditions in Philadelphia, Pennsylvania, USA at multiple scales. Applied Geography, 35(1-2), 257-264. 
126. Peng, Q., Li, Z., Chen, J., \& Liu, W. (2021). Complexity-based matching between image resolution and map scale for multiscale image-map generation. International Journal of Geographical Information Science, 35(10), 1951-1974.

127. Pereira, G. M. (2002). A Typology of Spatial and Temporal Scale Relations. Geographical Analysis, 34(1), 21-33.

128. Perveen, S., \& James, L. A. (2011). Scale invariance of water stress and scarcity indicators: Facilitating cross-scale comparisons of water resources vulnerability. Applied Geography, 31(1), 321-328.

129.

130. Petrović, A., van Ham, M., \& Manley, D. (2018). Multiscale Measures of Population: Within- and between-City Variation in Exposure to the Sociospatial Context. Annals of the American Association of Geographers, 108(4), 1057-1074.

131. Petrović, A., van Ham, M., \& Manley, D. (2021). Where Do Neighborhood Effects End? Moving to Multiscale Spatial Contextual Effects. Annals of the American Association of Geographers, 1-21.

132. Phillips, J. D. (1986). Spatial Analysis of Shoreline Erosion, Delaware Bay, New Jersey. Annals of the Association of American Geographers, 76(1), 50-62. JSTOR.

133. Phillips, J. D. (1988). The Role of Spatial Scale in Geomorphic Systems. Geographical Analysis, 20(4), 308-317.

134. Phillips, J. D. (2005). Entropy Analysis of Multiple Scale Causality and Qualitative Causal Shifts in Spatial Systems. The Professional Geographer, 57(1), 12.

135. Phillips, M., Page, S., Saratsi, E., Tansey, K., \& Moore, K. (2008). Diversity, scale and green landscapes in the gentrification process: Traversing ecological and social science perspectives. Applied Geography, 28(1), 54-76.

136. Pigozzi, B. W. (2004). A Hierarchy of Spatial Marginality Through Spatial Filtering. The Professional Geographer, 56(4), 12.

137. Plumejeaud, C., Mathian, H., Gensel, J., \& Grasland, C. (2011). Spatio-temporal analysis of territorial changes from a multi-scale perspective. International Journal of Geographical Information Science, 25(10), 1597-1612.

138. Pontius, R. G., Peethambaram, S., \& Castella, J.-C. (2011). Comparison of Three Maps at Multiple Resolutions: A Case Study of Land Change Simulation in Cho Don District, Vietnam. Annals of the Association of American Geographers, 101(1), 45-62. 
139. Propastin, P. (2011). Multiscale analysis of the relationship between topography and aboveground biomass in the tropical rainforests of Sulawesi, Indonesia. International Journal of Geographical Information Science, 25(3), 455-472.

140. Rennermalm, A. K., Bring, A., \& Mote, T. L. (2012). Spatial and Scale-Dependent Controls on North American Pan-Arctic Minimum River Discharge: NA Pan-Arctic Minimum Discharge. Geographical Analysis, 44(3), 202-218.

141. Rogerson, P. A., \& Kedron, P. (2012). Optimal Weights for Focused Tests of Clustering Using the Local Moran Statistic. Geographical Analysis, 44(2), 121-133.

142. Rogerson, P. A. (2015). Maximum Getis-Ord Statistic Adjusted for Spatially Autocorrelated Data. Geographical Analysis, 47(1), 20-33.

143. Root, E. D. (2012). Moving Neighborhoods and Health Research Forward: Using Geographic Methods to Examine the Role of Spatial Scale in Neighborhood Effects on Health. Annals of the Association of American Geographers, 102(5), 986-995.

144. Salvati, L., Benassi, F., Miccoli, S., Rabiei-Dastjerdi, H., \& Matthews, S. A. (2020). Spatial variability of total fertility rate and crude birth rate in a low-fertility country: Patterns and trends in regional and local scale heterogeneity across Italy, 2002-2018. Applied Geography, 124, 102321.

145. Shabrina, Z., Buyuklieva, B., \& Ng, M. K. M. (2021). Short-Term Rental Platform in the Urban Tourism Context: A Geographically Weighted Regression (GWR) and a Multiscale GWR (MGWR) Approaches. Geographical Analysis, 53(4), 686-707.

146. Shiode, S., \& Shiode, N. (2009). Detection of multi-scale clusters in network space. International Journal of Geographical Information Science, 23(1), 75-92.

147. Š́mová, P., \& Gdulová, K. (2012). Landscape indices behavior: A review of scale effects. Applied Geography, 34, 385-394.

148. Sinha, G., \& Silavisesrith, W. (2012). Multicriteria generalization (MCG): A decision-making framework for formalizing multiscale environmental data reduction. International Journal of Geographical Information Science, 26(5), 899-922.

149. Smith, T. E. (2004). A Scale-Sensitive Test of Attraction and Repulsion Between Spatial Point Patterns. Geographical Analysis, 36(4), 315-331.

150. Southworth, J., Cumming, G. S., Marsik, M., \& Binford, M. W. (2006). Linking Spatial and Temporal Variation at Multiple Scales in a Heterogeneous Landscape*. The Professional Geographer, 58(4), 406-420. 
151. Stefanidis, A., Agouris, P., Georgiadis, C., Bertolotto, M., \& Carswell, J. D. (2002). Scale- and orientation-invariant scene similarity metrics for image queries. International Journal of Geographical Information Science, 16(8), 749-772.

152. Stoms, D. M. (1994). Scale dependence of species richness maps. Professional Geographer, 46(3), 346.

153. Stoter, J., Visser, T., van Oosterom, P., Quak, W., \& Bakker, N. (2011). A semantic-rich multi-scale information model for topography. International Journal of Geographical Information Science, 25(5), 739-763.

154. Su, S., Xiao, R., \& Zhang, Y. (2012). Multi-scale analysis of spatially varying relationships between agricultural landscape patterns and urbanization using geographically weighted regression. Applied Geography, 32(2), 360-375.

155. Sun, B., \& Yin, C. (2018). Relationship between multi-scale urban built environments and body mass index: A study of China. Applied Geography, 94, $230-240$.

156. Tan, X., Huang, B., Batty, M., \& Li, J. (2021). Urban Spatial Organization, Multifractals, and Evolutionary Patterns in Large Cities. Annals of the American Association of Geographers, 111(5), 1539-1558.

157. Tang, W., \& Bennett, D. A. (2010). The Explicit Representation of Context in Agent-Based Models of Complex Adaptive Spatial Systems. Annals of the Association of American Geographers, 100(5), 1128-1155.

158. Thornes, J. B. (2010). Markov Chains and Slope Series: The Scale Problem. Geographical Analysis, 5(4), 322-328.

159. Tian, Q., Brown, D. G., Zheng, L., Qi, S., Liu, Y., \& Jiang, L. (2015). The Role of Cross-Scale Social and Environmental Contexts in Household-Level Land-Use Decisions, Poyang Lake Region, China. Annals of the Association of American Geographers, 105(6), 1240-1259.

160. van Oosterom, P. (1995). The development of an interactive multi-scale GIS. International Journal of Geographic Information Systems, 9(5).

161. van Oosterom, P., \& Meijers, M. (2014). Vario-scale data structures supporting smooth zoom and progressive transfer of 2D and 3D data. International Journal of Geographical Information Science, 28(3), 455-478.

162. Van de Weghe, N., de Roo, B., Qiang, Y., Versichele, M., Neutens, T., \& de Maeyer, P. (2014). The continuous spatio-temporal model (CSTM) as an exhaustive framework 
for multi-scale spatio-temporal analysis. International Journal of Geographical Information Science, 28(5), 1047-1060.

163. Van Den Hoek, J., Ozdogan, M., Burnicki, A., \& Zhu, A.-X. (2014). Evaluating forest policy implementation effectiveness with a cross-scale remote sensing analysis in a priority conservation area of Southwest China. Applied Geography, 47, 177-189.

164. Verfaillie, E., Du Four, I., Van Meirvenne, M., \& Van Lancker, V. (2009). Geostatistical modeling of sedimentological parameters using multi-scale terrain variables: Application along the Belgian Part of the North Sea. International Journal of Geographical Information Science, 23(2), 135-150.

165. Vu, T.-T., Thy, P. T. M., \& Nguyen, L. Đ. (2018). Multiscale remote sensing of urbanization in Ho Chi Minh city, Vietnam-A focused study of the south. Applied Geography, 92, 168-181.

166. Weiss, D. J., Malanson, G. P., \& Walsh, S. J. (2015). Multiscale Relationships Between Alpine Treeline Elevation and Hypothesized Environmental Controls in the Western United States. Annals of the Association of American Geographers, 105(3), 437-453.

167. Walker, R. (2012). The scale of forest transition: Amazonia and the Atlantic forests of Brazil. Applied Geography, 32(1), 12-20.

168. Westerholt, R., Resch, B., \& Zipf, A. (2015). A local scale-sensitive indicator of spatial autocorrelation for assessing high- and low-value clusters in multiscale datasets. International Journal of Geographical Information Science, 29(5), 868-887.

169. Williams, R. L. (1959). Map Projections, Linear Scale, and the Representative Fraction. Annals of the Association of American Geographers, 49(1), 88-88.

170. Wilson, A. M., Silander, J. A., Gelfand, A., \& Glenn, J. H. (2011). Scaling up: Linking field data and remote sensing with a hierarchical model. International Journal of Geographical Information Science, 25(3), 509-521.

171. Wolf, L. J., Oshan, T. M., \& Fotheringham, A. S. (2018). Single and Multiscale Models of Process Spatial Heterogeneity. Geographical Analysis, 50(3), 223-246.

172. Wong, D. W. S. (2001). Location-Specific Cumulative Distribution Function (LSCDF): An Alternative to Spatial Correlation Analysis. Geographical Analysis, 33(1), 76-93.

173. Wong, D. W. S. (2003). Spatial Decomposition of Segregation Indices: A Framework Toward Measuring Segregation at Multiple Levels. Geographical Analysis, 35(3), 179-194. 
174. Wright, R., Ellis, M., Holloway, S. R., \& Wong, S. (2014). Patterns of Racial Diversity and Segregation in the United States: 1990-2010. The Professional Geographer, 66(2), 173-182.

175. Wu, H., Li, Z., Clarke, K. C., Shi, W., Fang, L., Lin, A., \& Zhou, J. (2019a). Examining the sensitivity of spatial scale in cellular automata Markov chain simulation of land use change. International Journal of Geographical Information Science, 33(5), 1040-1061.

176. Wu, C., Ren, F., Ye, X., Liang, X., \& Du, Q. (2019b). Spatiotemporal analysis of multiscale income mobility in China. Applied Geography, 111, 102060.

177. Wu, C., Ren, F., Hu, W., \& Du, Q. (2019c). Multiscale geographically and temporally weighted regression: Exploring the spatiotemporal determinants of housing prices. International Journal of Geographical Information Science, 33(3), 489-511.

178. Wu, S., Wang, Z., Du, Z., Huang, B., Zhang, F., \& Liu, R. (2021a). Geographically and temporally neural network weighted regression for modeling spatiotemporal non-stationary relationships. International Journal of Geographical Information Science, 35(3), 582-608.

179. Wu, B., Yan, J., \& Lin, H. (2021b). A cost-effective algorithm for calibrating multiscale geographically weighted regression models. International Journal of Geographical Information Science, 1-20.

180. Xu, T., Gao, J., Coco, G., \& Wang, S. (2020). Urban expansion in Auckland, New Zealand: A GIS simulation via an intelligent self-adapting multiscale agent-based model. International Journal of Geographical Information Science, 34(11), 2136-2159.

181. Yamada, I., Brown, B. B., Smith, K. R., Zick, C. D., Kowaleski-Jones, L., \& Fan, J. X. (2012). Mixed Land Use and Obesity: An Empirical Comparison of Alternative Land Use Measures and Geographic Scales. The Professional Geographer, 64(2), $157-177$.

182. Yoo, E.-H., \& Trgovac, A. B. (2011). Scale effects in uncertainty modeling of presettlement vegetation distribution. International Journal of Geographical Information Science, 25(3), 405-421.

183. Yue, L., Shen, H., Yuan, Q., \& Zhang, L. (2015). Fusion of multi-scale DEMs using a regularized super-resolution method. International Journal of Geographical Information Science, 29(12), 2095-2120. 
184. Yu, H., Fotheringham, A. S., Li, Z., Oshan, T., Kang, W., \& Wolf, L. J. (2020). Inference in Multiscale Geographically Weighted Regression. Geographical Analysis, 52(1), 87-106.

185. Yu, H., \& Fotheringham, A. S. (2021). A multiscale measure of spatial dependence based on a discrete Fourier transform. International Journal of Geographical Information Science, 1-24.

186. Zhang, N., \& Zhang, H. (2011). Scale variance analysis coupled with Moran's I scalogram to identify hierarchy and characteristic scale. International Journal of Geographical Information Science, 25(9), 1525-1543.

187. Zhang, S., York, A. M., Boone, C. G., \& Shrestha, M. (2013). Methodological Advances in the Spatial Analysis of Land Fragmentation. The Professional Geographer, 65(3), 512-526.

188. Zhang, Z., Su, S., Xiao, R., Jiang, D., \& Wu, J. (2013). Identifying determinants of urban growth from a multi-scale perspective: A case study of the urban agglomeration around Hangzhou Bay, China. Applied Geography, 45, 193-202.

189. Zhang, C., Lin, H., Chen, M., Li, R., \& Zeng, Z. (2014). Scale compatibility analysis in geographic process research: A case study of a meteorological simulation in Hong Kong. Applied Geography, 52, 135-143.

190. Zhang, C., Chen, M., Li, R., Ding, Y., \& Lin, H. (2015). A virtual geographic environment system for multiscale air quality analysis and decision making: A case study of SO2 concentration simulation. Applied Geography, 63, 326-336.

191. Zhang, B., Xu, G., Jiao, L., Liu, J., Dong, T., Li, Z., Liu, X., \& Liu, Y. (2019). The scale effects of the spatial autocorrelation measurement: Aggregation level and spatial resolution. International Journal of Geographical Information Science, 33(5), 945-966.

192. Zhang, Z., Li, J., Fung, T., Yu, H., Mei, C., Leung, Y., \& Zhou, Y. (2021). Multiscale geographically and temporally weighted regression with a unilateral temporal weighting scheme and its application in the analysis of spatiotemporal characteristics of house prices in Beijing. International Journal of Geographical Information Science, 35(11), 2262-2286.

193. Zhang, W.-B., Ge, Y., Leung, Y., \& Zhou, Y. (2021). A georeferenced graph model for geospatial data matching by optimising measures of similarity across multiple scales. International Journal of Geographical Information Science, 35(11), 2339-2355.

194. Zhao, R., Pang, M., \& Wang, J. (2018). Classifying airborne LiDAR point clouds via deep features learned by a multi-scale convolutional neural network. International Journal of Geographical Information Science, 32(5), 960-979. 


\section{Appendix}

Table A.1: Additional descriptions of the five selected journals

\begin{tabular}{|c|c|}
\hline Journal & Summary of scope \\
\hline AAAG & $\begin{array}{l}\text { "...major research articles for all fields of geography...must adhere to a high standard of } \\
\text { scholarship and make an important contribution to geographic knowledge. It should also be } \\
\text { grounded in the relevant literature of the specialization it represents and, where appropriate, } \\
\text { establish relationships to themes within the broader discipline." }\end{array}$ \\
\hline TPG & $\begin{array}{l}\text { "...short articles in academic or applied geography, emphasizing empirical studies and } \\
\text { methodologies...may range in content and approach from rigorously analytic to broadly } \\
\text { philosophical or prescriptive....provides a forum for new ideas and alternative viewpoints." }\end{array}$ \\
\hline APGEO & $\begin{array}{l}\text { “...research which utilizes geographic approaches (human, physical, nature-society and } \\
\text { GIScience) to resolve human problems that have a spatial dimension... any theme involving } \\
\text { the application of geographical theory and methodology in the resolution of human } \\
\text { problems. This may include papers on the techniques, problems and results of } \\
\text { environmental and/or social research, as well as those concerned with the principles, } \\
\text { policies and consequences of resource management and allocation." }\end{array}$ \\
\hline GEAN & $\begin{array}{l}\text { "...advances in geographical theory, model building, and quantitative methods to } \\
\text { geographers and scholars in a wide spectrum of related fields. Traditionally, mathematical } \\
\text { and nonmathematical articulations of geographical theory, and statements and discussions of } \\
\text { the analytic paradigm..." }\end{array}$ \\
\hline IJGIS & $\begin{array}{l}\text { "...ideas, approaches, methods and experiences in the rapidly growing field of geographical } \\
\text { information science...fundamental and computational issues of geographic information, as } \\
\text { well as issues related to the design, implementation and use of geographical information for } \\
\text { monitoring, prediction and decision making...innovations in GIScience and novel } \\
\text { applications of GIScience in natural resources, social systems and the built environment, as } \\
\text { well as relevant developments in computer science, cartography, surveying, geography and } \\
\text { engineering in both developed and developing countries...directed at those with skills in } \\
\text { designing and using GIS, database management, computer graphics and analysis of spatial } \\
\text { data, as well as those in planning and decision-making using GIS." }\end{array}$ \\
\hline
\end{tabular}


Table A.2: Tally of topics detected in each journal and across all journals.

\begin{tabular}{|c|c|c|c|c|c|c|}
\hline & $\mathbf{A A A G}$ & TPG & APGEO & GEAN & IJGIS & Total \\
\hline Data Structures \& Analytics & 17 & 10 & 2 & 26 & 52 & 107 \\
\hline Land Use \& Urbanization & 4 & 4 & 23 & 2 & 11 & 45 \\
\hline Landscape \& Terrain & 6 & 3 & 12 & 3 & 16 & 39 \\
\hline Demography & 6 & 6 & 3 & 7 & 2 & 24 \\
\hline Vegetation & 6 & 3 & 2 & 0 & 6 & 17 \\
\hline Economic Development & 0 & 1 & 9 & 2 & 3 & 15 \\
\hline Heath & 2 & 2 & 6 & 0 & 2 & 15 \\
\hline Human-Environment & 1 & 0 & 9 & 0 & 3 & 13 \\
\hline Water \& Coasts & 1 & 1 & 5 & 1 & 2 & 10 \\
\hline Animals & 2 & 1 & 3 & 0 & 4 & 10 \\
\hline Climate \& Atmosphere & 2 & 0 & 5 & 0 & 3 & 10 \\
\hline Disaster \& Risk Management & 0 & 1 & 6 & 0 & 2 & 9 \\
\hline Geomorphology & 1 & 0 & 1 & 3 & 1 & 6 \\
\hline Soil & 1 & 1 & 2 & 1 & 0 & 5 \\
\hline Transportation & 0 & 0 & 1 & 0 & 4 & 5 \\
\hline Ecosystems & 1 & 1 & 2 & 0 & 1 & 6 \\
\hline Politics & 2 & 0 & 0 & 2 & 0 & 4 \\
\hline Crime & 0 & 0 & 1 & 1 & 0 & 2 \\
\hline
\end{tabular}


Table A.3: Disaggregation of the sub-topics in the Data Structures and Analytics topic.

\begin{tabular}{|l|l|}
\hline \multicolumn{1}{|c|}{ Sub-topic } & Occurrences \\
\hline Decomposition Models & 26 \\
\hline Cartography \& GIS & 21 \\
\hline Profiling & 13 \\
\hline Clustering & 14 \\
\hline Scaling \& Fractals & 11 \\
\hline Rescaling & 7 \\
\hline Remote Sensing \& Image Processing & 7 \\
\hline Agents & 7 \\
\hline MAUP & 5 \\
\hline Conceptual & 3 \\
\hline Other & - \\
\hline
\end{tabular}

